\title{
Use of IL-1 $\beta$, IL-6, TNF- $\alpha$, and MMP-8 biomarkers to distinguish peri-implant diseases: A systematic review and meta-analysis
}

\author{
Iya Ghassib DDS ${ }^{1}$ @ | Zhaozhao Chen DDS, MS $^{1,2}$ @ | Juanfang Zhu DDS, PhD $^{1,3}$ | \\ Hom-Lay Wang DDS, MS, $\mathrm{PhD}^{1}$ ()
}

${ }^{1}$ Department of Periodontics and Oral Medicine, University of Michigan School of Dentistry, Ann Arbor, Michigan

${ }^{2}$ State Key Laboratory of Oral Diseases, National Clinical Research Center for Oral Disease, Department of Prosthodontics, West China Hospital of Stomatology, Sichuan University, Chengdu, People's Republic of China

${ }^{3}$ Department of Stomatology, The First Affiliated Hospital of Zhengzhou University, Zhengzhou, Henan, People's Republic of China

Correspondence

Hom-Lay Wang, Department of Periodontics and Oral Medicine, University of Michigan School of Dentistry, 1011 North University Avenue, Ann Arbor, MI 48109-1078.

Email: homlay@umich.edu

Funding information

University of Michigan

\begin{abstract}

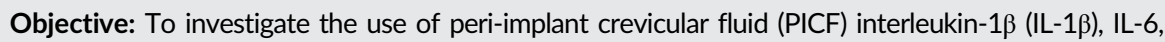
tumor necrosis factor- $\alpha$ (TNF- $\alpha$ ), and matrix metalloproteinase-8 (MMP-8) biomarkers in distinguishing between healthy implants $(\mathrm{H})$, peri-implant mucositis (MU), and peri-implantitis (PI).

Material and Methods: Electronic using three databases (Pubmed, EMBASE, and Cochrane) and manual searches were conducted for articles published up to March 2018 by two independent calibrated reviewers. Meta-analyses using a random-effects model were conducted for each of the cytokines; IL-1 $\beta$, IL- 6 , and TNF- $\alpha$, to analyze standardized mean difference (SMD) between $\mathrm{H}$ and $\mathrm{MU}, \mathrm{MU}$ and $\mathrm{PI}, \mathrm{H}$ and $\mathrm{PI}$ with their associated $95 \%$ confidence intervals (CI). Qualitative assessment of MMP-8 was provided consequent to the lack of studies that provide valid data for a meta-analysis.

Results: Nineteen articles were included in this review. IL-1 $\beta$, IL-6, and TNF- $\alpha$, levels were significantly higher in $\mathrm{MU}$ than $\mathrm{H}$ groups (SMD: 1.94; 95\% Cl: 0.87, 3.35; $P$ < .001, SMD: 1.17; 95\% Cl: 0.16, 3.19; $P=.031$ and SMD: 3.91; 95\% Cl: 1.13, 6.70; $P=.006$, respectively). Similar results were obtained with $\mathrm{PI}$ compared to $\mathrm{H}$ sites (SMD: $2.21,95 \% \mathrm{Cl}: 1.32,3.11 ; \mathrm{P}<.001$, SMD: 1.72; 95\% Cl: 0.56, 2.87; $P=.004$ and SMD: 3.78; 95\% Cl: 1.67, 5.89; $P<.001$, respectively). IL-6 was statistically higher in PI than $\mathrm{MU}$ sites $(\mathrm{SMD}=1.46 ; 95 \% \mathrm{Cl}: 0.36,2.55$; $P=.009$ ); while IL-1ß increase was not significant. Despite absence of meta-analysis, MMP-8 show to be a promising biomarker in detection of $\mathrm{PI}$ in literature.

Conclusion: Within the limitations of this study, pro-inflammatory cytokines in PICF, such as IL$1 B$ and IL-6, can be used as adjunct tools to clinical parameters to differentiate $H$ from $M U$ and PI.
\end{abstract}

\section{KEYWORDS}

cytokines inflammation, dental implants, meta-analysis, systematic review

\section{INTRODCUTION}

"Peri-implant diseases" collectively describe plaque-associated pathological conditions that develop inflammatory lesions in tissues around implants. ${ }^{1}$ A continuum exists between health and peri-implant diseases, categorized into peri-implant mucositis (MU) and periimplantitis (PI). $\mathrm{MU}$ is the precursor to $\mathrm{PI}$, with around $43 \%-48 \%$ prevalence rate among implants. ${ }^{2-4} \mathrm{PI}$ is distinguished by progressive loss of supporting bone beyond initial biological bone remodeling; when compared to $\mathrm{MU},{ }^{5}$ and has a prevalence rate of $12 \%-43 \%{ }^{1,6}$

Clinical and radiographic evaluations are the most used methods in diagnosing $\mathrm{MU}$ and $\mathrm{Pl}$. Although easily applicable, clinical parameters alone do not assess the risk rate, onset, activity, and progression of peri-implant destructive changes. ${ }^{7-10}$ Biomarkers are host response molecules that have been investigated in determining disease and its severity in conjunction with clinical assessment. ${ }^{11,12}$ Pro-inflammatory 
cytokines are some of the most investigated biomarkers in periimplant diseases, as they play an important role in cascading inflammatory responses that are cellular and vascular. ${ }^{13}$ The presence of polymorphonuclear cells (PMN) and abundance of fibroblast matrix metalloproteinase-8 (MMP-8) had also been shown to be pertinent to the early detection of $\mathrm{PI}$, which usually follows the release of those cytokines. ${ }^{14,15}$ The destruction of connective tissue is a significant determinant of the progression of peri-implant lesions that is essentially driven by MMP-8. This collagenase is known to be the major MMP detected in periodontitis and is thought to be a potential biomarker of PI.

IL-1 $\beta$, TNF- $\alpha$, IL-6, and MMP-8 have been investigated in conjunction with bleeding on probing, gingival index, and probing depths, to prevent and profoundly comprehend pathogenesis of peri-implant diseases. ${ }^{16}$ Their concentrations also vary markedly in normal biologic, pathogenic conditions as well as after therapeutic interventions. ${ }^{17}$ Peri-implant crevicular fluid (PICF), similar to gingival crevicular fluid around teeth, can be an indicator of inflammatory exudates, through which those biomarkers could be collected. PICF is easily accessible, non-invasive, and sequentially determinable; therefore, if variation in cytokine and MMP-8 levels matches severity and classification of diseases in reference to health, routine biomarkers testing could become a personalized diagnostic tool in clinical practice. ${ }^{11,18}$

A published systematic review and meta-analysis, including articles up to 2013, investigated TNF- $\alpha$ and IL-1 $\beta$ in PICF, showing robust levels in disease compared to health, but no significant difference between $\mathrm{MU}$ and $\mathrm{PI}{ }^{19}$ Nonetheless, the extent of inflammation markedly increases from $\mathrm{MU}$ to $\mathrm{PI}$, as shown by the majority of clinical studies. Additionally, IL-6 is one of the most investigated proinflammatory cytokines between healthy and diseased peri-implant tissues. ${ }^{20-25}$ MMP-8 was very useful to monitor the rapid destruction of connective tissue that marks the progression of MU and PI. ${ }^{18,26}$

Hence, this study aimed at (1) investigating the potential use of IL-1 $\beta$, IL- 6 , TNF- $\alpha$, and MMP-8, as biomarkers of implants health, periimplant mucositis, and peri-implantitis conditions in PICF; (2) attempting to develop a recognizable pattern of cytokines and MMP-8 release; and (3) identifying factors that may influence results of previous studies to minimize discrepancies in future investigations.

\section{2 | MATERIAL AND METHODS}

This systematic review and meta-analysis was performed and written following the 27-item PRISMA (Preferred Reporting Items for Systematic Reviews and Meta-Analyses) statement (Moher et al 2009). The PRISMA checklist is attached to the appendix of this article (Supporting Information Checklist 1).

\subsection{Focus question}

The focus question was developed considering the Population, Intervention, Comparison, and Outcome (PICO) elements (Stone 2002) and as follows: Could cytokine and MMP-8 levels in the PICF be used to distinguish between health $(\mathrm{H}), \mathrm{MU}$, and $\mathrm{PI}$ ?

P: Systemically healthy subjects who received dental implants.
I: IL-1 $\beta$, IL-6, TNF- $\alpha$, and MMP-8 biomarkers can be used to differentiate between $\mathrm{H}, \mathrm{MU}$, and $\mathrm{PI}$.

$\mathrm{C}$ : Investigating the presence or absence of a difference in the cytokine and MMP-8 levels between implants with $\mathrm{H}, \mathrm{MU}$, and $\mathrm{PI}$.

O: There is a difference in the level of IL-1 $\beta$, IL-6, TNF- $\alpha$, and MMP-8 between (1) H versus MU; (2) H versus $\mathrm{Pl}$; and (3) MU versus $\mathrm{PI}$.

\section{2 | Search strategy}

Electronic and manual literature searches were conducted by two reviewers (IG, ZC) independently, using PubMed/MEDLINE, EMBASE, and Cochrane Library up to March 2018 without language restriction. For the PubMed library, the search terms were as follows: (dental implant[MeSH Terms]) OR dental implantation[MeSH Terms]) OR implant[Title/Abstract]) OR peri-implant crevicular fluid[Title/ Abstract]) OR PICF[Title/Abstract]) OR peri-implant sulcus fluid[Title/ Abstract]) OR PSF[Title/Abstract]) AND (cytokines[MeSH Terms]) OR biomarkers[MeSH Terms]) OR interlukin[Title/Abstract]) OR IL[Title/ Abstract]) OR tumor necrosis factor[Title/Abstract]) OR TNF[Title/ Abstract] OR MMP-8[Title/Abstract]). For the EMBASE, the search strategy was: ("tooth implantation"/de OR "tooth implant"/exp OR "dental implant":ti,ab,kw) AND ("biological marker"/de OR "cytokine"/ exp OR "biomarker":ti,ab,kw OR "interlukin":ti,ab,kw OR "tumor necrosis factor":ti,ab,kw). For the Cochrane Library, (cytokine OR biomarker) AND implant was applied in Title, Abstract, and Keywords in Trials.

Additionally, to complete the survey, a manual search of periodontics/implantology-related journals from March 1995 to March 2018, including Journal of Clinical Periodontology, Clinical Oral Implants Research, Journal of Periodontology, Clinical Implant Dentistry and Related Research, European Journal of Oral Implantology, International Journal of Oral and Maxillofacial Implants, Implant Dentistry, Journal of Oral Implantology, International Journal of Oral and Maxillofacial Surgery, Journal of Oral and Maxillofacial Surgery and International Journal of Periodontics and Restorative Dentistry. The related reviews ${ }^{9,19,27}$ and references of selected studies were further scanned for potentially relevant articles.

According to the selection criteria, titles and abstracts of the search results were screened, and then the full-text articles screen was conducted. The level of agreement between the reviewers (IG, ZC) for potentially relevant articles was calculated using $k$ statistics. A consent on final decision was reached by discussion with the senior author (HLW).

\subsection{Data extraction and selection criteria}

Data from the eligible studies were extracted by two reviewers (IG, $J Z$ independently. The inter-reviewer disagreement was resolved by discussion as well as consultation with senior author (HLW). Corresponding authors were contacted in cases of missing or unclear data.

For this systematic review, eligible studies met the following inclusion criteria: (1) original cross-sectional and longitudinal prospective clinical studies with the collection of pro-inflammatory cytokines in PICF from individuals with PI or MU; (2) studies analyzed protein 
expression by enzyme-linked immunosorbent assay (ELISA) or flow cytometry using a cytometric bead array system. The exclusion criteria comprised of: (1) animal, in vitro studies, case reports, and reviews; (2) studies with quantification of pro-inflammatory cytokines in tissue biopsies or saliva; (3) only analysis of osteogenic markers; (4) unreported exact numbers of cytokine levels; (5) fluid collection during early osseointegration; (6) unclear peri-implant disease criteria; and (7) unreported anti-inflammatory and antibiotic medication in inclusion criteria.

\section{4 | Risk of bias assessment}

The criteria used to assess the quality of selected studies is the NIH Quality Assessment Tool for Observational Cohort and CrossSectional Studies. This constituted of 14 questions and provided guidelines for evaluating the research question, study population, exposure, outcomes, follow-up rate, and statistical analyses. Consequently, studies are rated good and fair. This was completed by two examiners (IG, ZC) independently. The possibility of publication bias (see Appendix Figure A1) was assessed with Egger linear plots for continuous-data elements. A significant publication bias is found if $P<.05 .^{28}$

\section{5 | Statistical analysis}

Stata 14.0 (StataCorp LP, College Station, Texas) was used to conduct all of the statistical analyses. The standardized mean difference (SMD) between two groups was analyzed with random effects model to compare the IL-1 $\beta$, IL- 6 , and TNF- $\alpha$ levels between $\mathrm{H}$ and $\mathrm{MU}, \mathrm{H}$ and $\mathrm{PI}$, as well as $\mathrm{MU}$ and PI. SMD was used rather than the weighted mean difference (WMD) since the measurement units for each biomarker varied between studies; that is, in accordance with Cochrane guidelines. ${ }^{29}$ Heterogeneity was estimated by the $Q$ statistic (significant at $P<.1$ ) and quantified with the $I^{2}$ test. The value of $I^{2} \geq 75 \%$ suggests high or "considerable/substantial" heterogeneity. Moderate
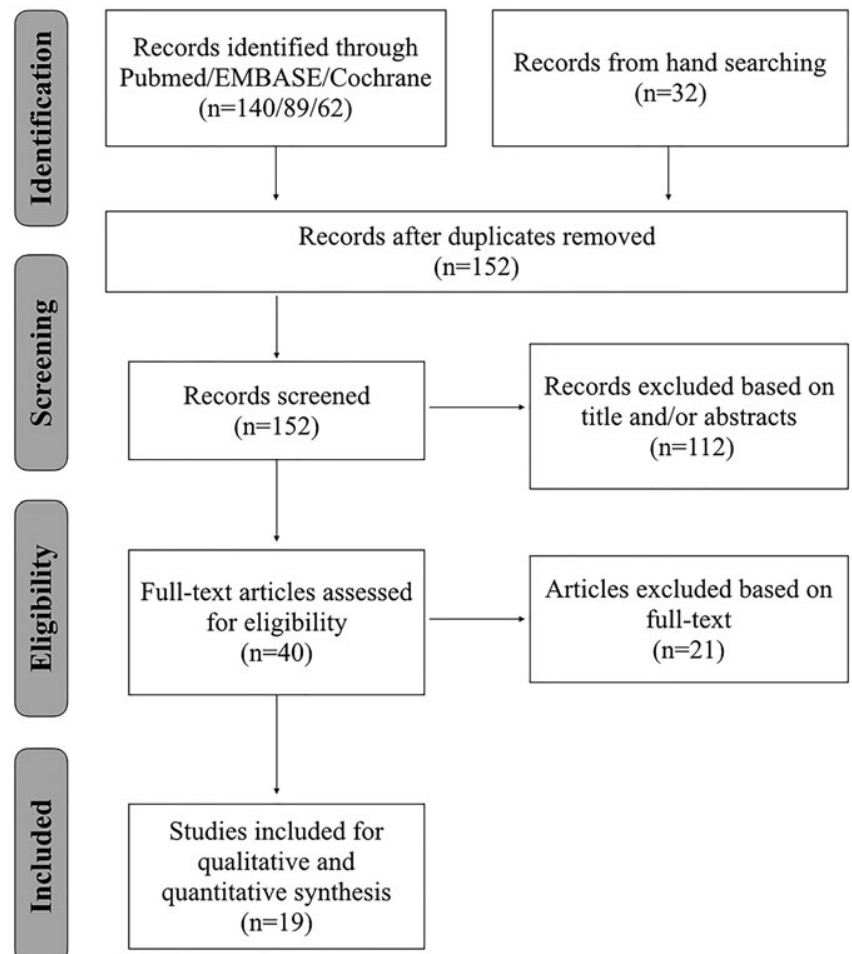

FIGURE 1 PRISMA flow diagram of the. Study selection process

heterogeneity is deduced from results showing 30\%-60\% and 0\%$40 \%$ may not be important. ${ }^{30}$ Galbraith plots analyses were conducted to investigate the potential source of heterogeneity among studies. ${ }^{31}$

\section{3 | RESULTS}

\section{1 | Study selection}

The literature selection process is illustrated by a PRISMA flowchart (Figure 1). Initial screening yielded a total of 291 records, 140 articles

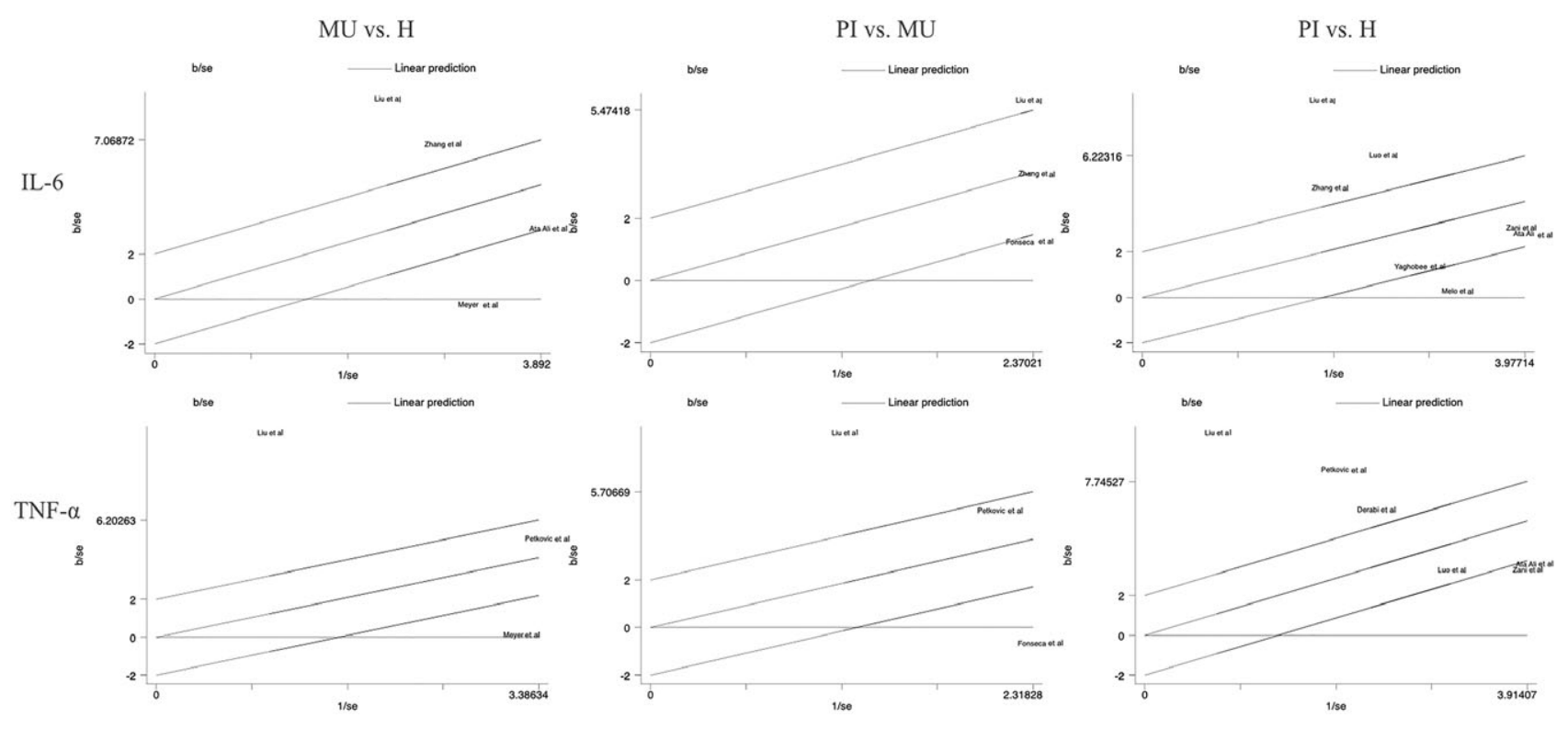

FIGURE A1 Galbraith plot assessing heterogeneity of studies included in the comparison of IL-6 (and TNF- $\alpha$ ) between $\mathrm{H}$ and MU, MU and PI, H and $\mathrm{PI}$ 
TABLE 1 Summary of excluded articles

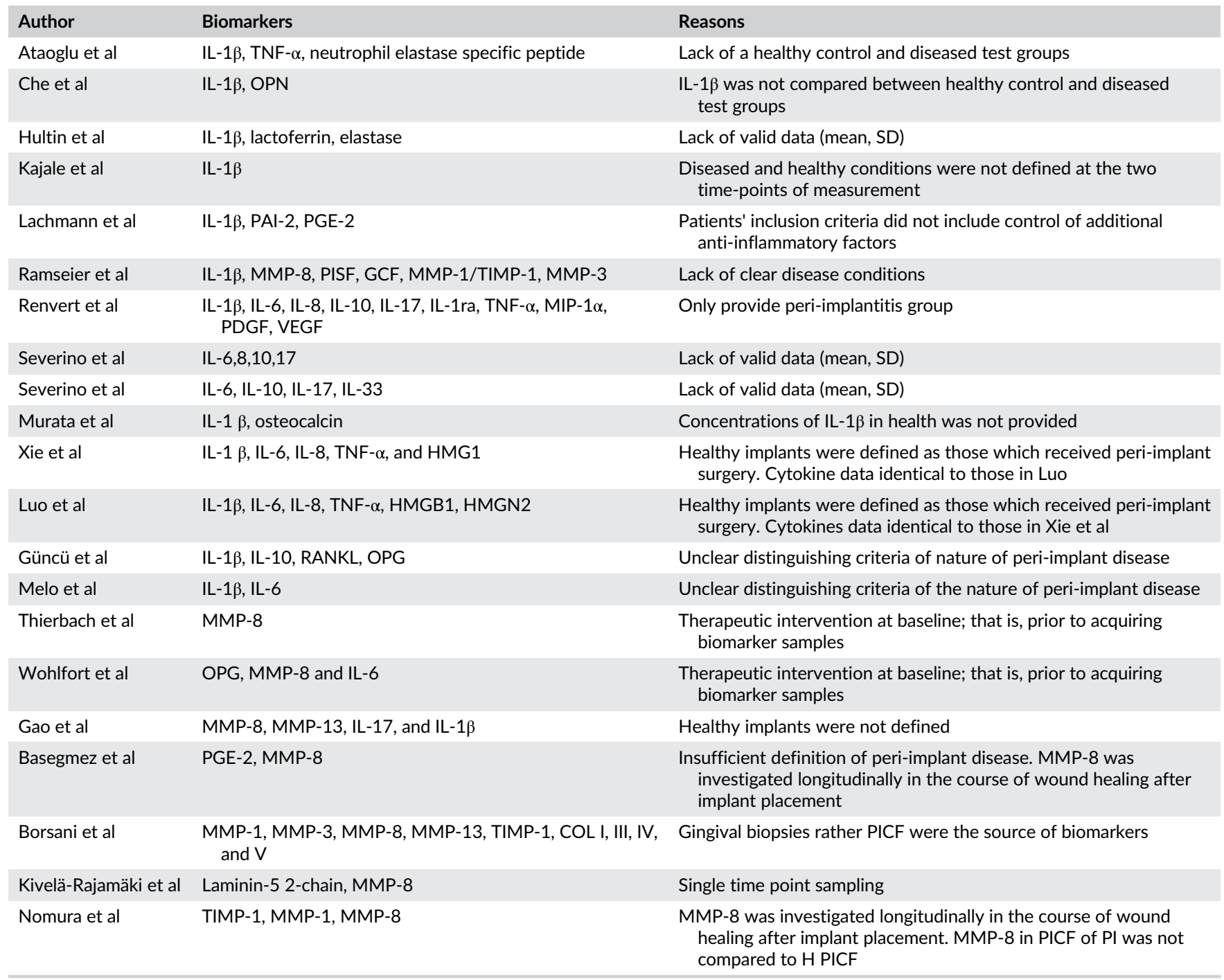

Abbreviations: COL, collagen, plasminogen activator inhibitor-2; HMGB1, high mobility group nucleosomal binding domain 2; ILs, interleukins; OPG, osteoprotegrin; RANKL, receptor activator of nuclear factor kappa-B ligand; TIMP, tissue inhibitor of metalloproteinases.

via PubMed, 89 via EMBASE, and 62 via Cochrane Library. Additionally, 32 records were found by hand-searching. After duplicates discarded, 152 records remained. The review of the titles and abstracts resulted in 42 articles selected for full-text screening, 21 of them were then excluded with reasons listed in Table 1 . Finally, 19 eligible articles $(26 ; 32 ; 33 ; 34 ; 35 ; 36 ; 37 ; 15 ; 38 ; 25 ; 24 ; 39 ; 23 ; 22 ; 40 ; 11 ; 2$; $41 ; 42)$ were included in this systematic review and quantitative synthesis. The details of the included studies are reported in Table 2. The $k$ value for inter-reviewer agreement of potentially relevant articles was 0.84 (title/abstract screening) and 0.89 (full-text screening), indicating a consistent agreement between the two reviewers. A consent on final decision was reached by discussion with another reviewer (HLW).

\subsection{Description of the studies}

The most studied cytokine was IL-1 $\beta(n=14)$, followed by IL-6 $(n=8)$ and TNF- $\alpha(n=6)$. Other cytokines, IL-4, IL-8, IL-10, IL-12, and IL-17, were also linked to peri-implant diseases. MMP-8 was investigated in 12 studies, of which eight were excluded.
All included studies were either cross-sectional or longitudinal experimental ones. Regarding the age of patients, the most common range was between 30 and 60 years. Meyer in 2017, showed the highest age group of patients, with a mean age of 77. Among the 19 included studies, five used ELISA R\&D System; a type of sandwich immunoassay where two highly specific antibodies are used to detect a target analyte. ${ }^{22,23,25,35,39}$ Eight used other ELISA kits, 2,11,15,26,32,36,38,42 two CBA assays, ${ }^{33,34}$ three multiplexes, ${ }^{25,37,40}$ and one Luminex kit. $^{41}$

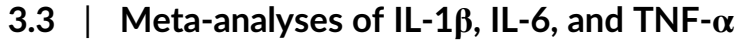

For IL-1 $\beta$, there were five articles ${ }^{22-25,35}$ comparing its level between $\mathrm{H}$ and $\mathrm{MU}$ (Figure 2A). In one article, ${ }^{23}$ there were two subgroup of $\mathrm{MU}$ (ie, early and advanced $\mathrm{MU}$ ), so we included both arms in metaanalysis. $\mathrm{MU}$ group showed significantly higher IL-1 $\beta$ level than $\mathrm{H}$ group (SMD: 1.94; 95\% Cl: 0.87, 3.35; $P<.001$ ). The heterogeneity between studies was significant $\left(I^{2}=92.1 \%, P<.001\right)$. The Galbraith plot (Figure 2B) showed that the considerable heterogeneity was generated by one study. ${ }^{25}$ With this study removed, the heterogeneity 


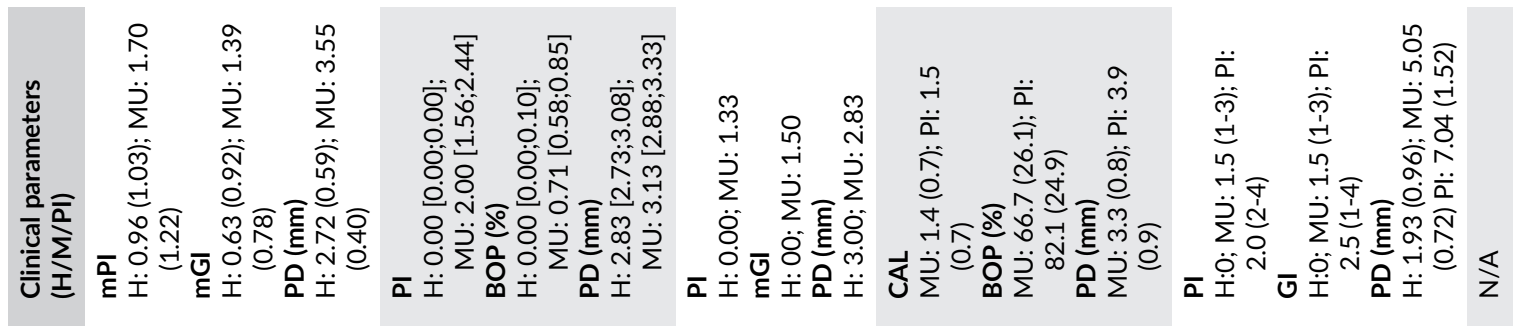
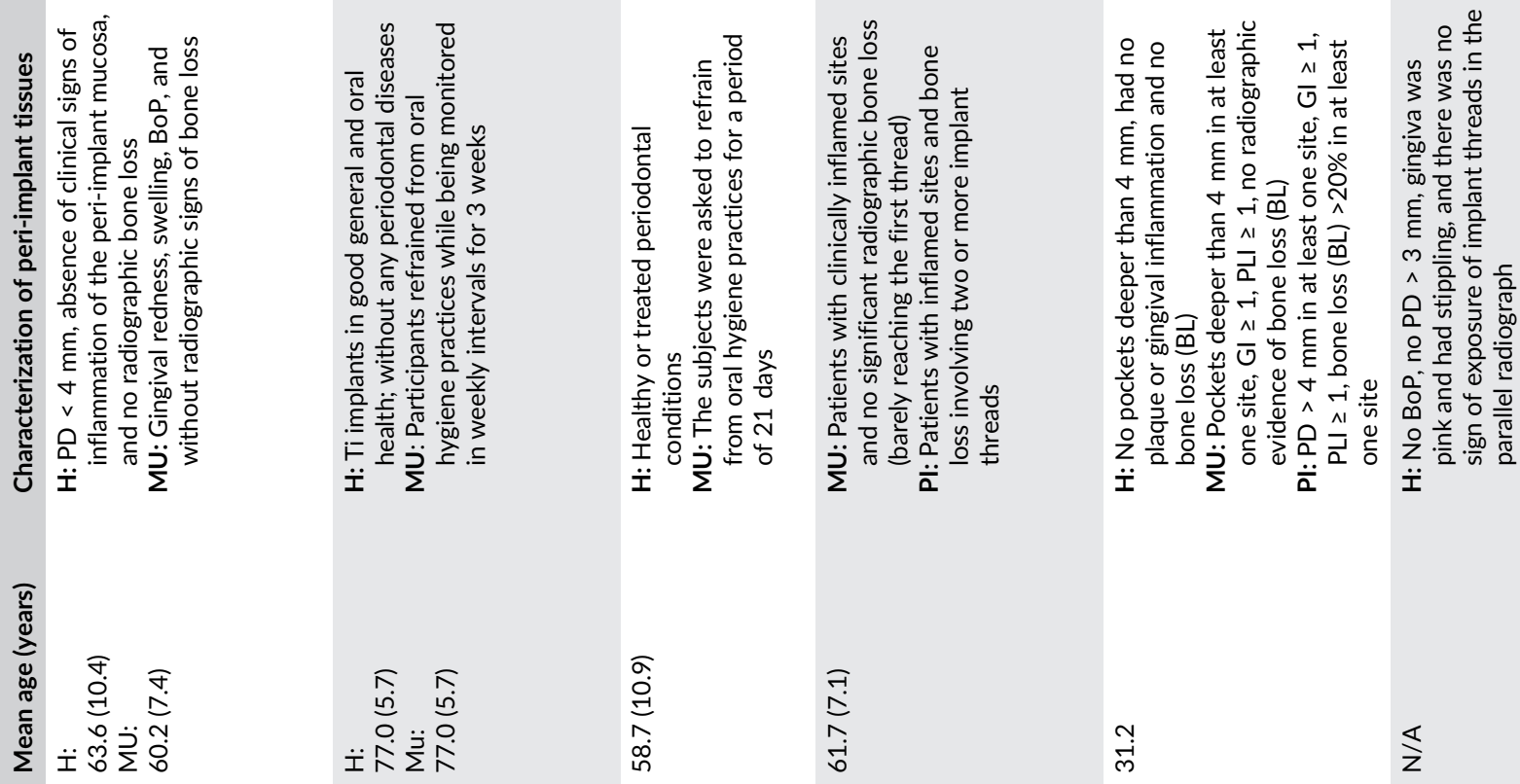

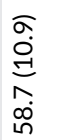



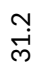

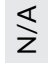
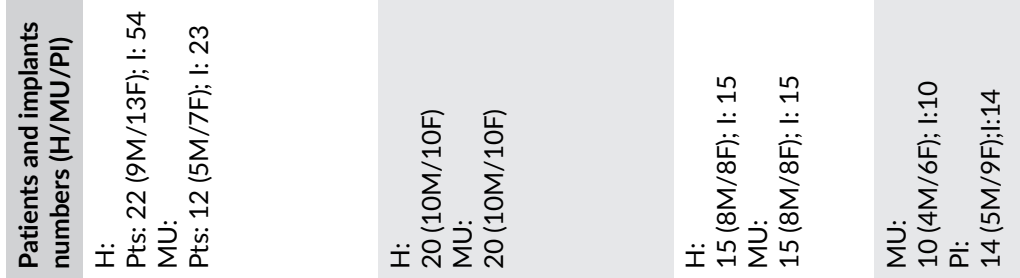

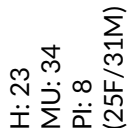
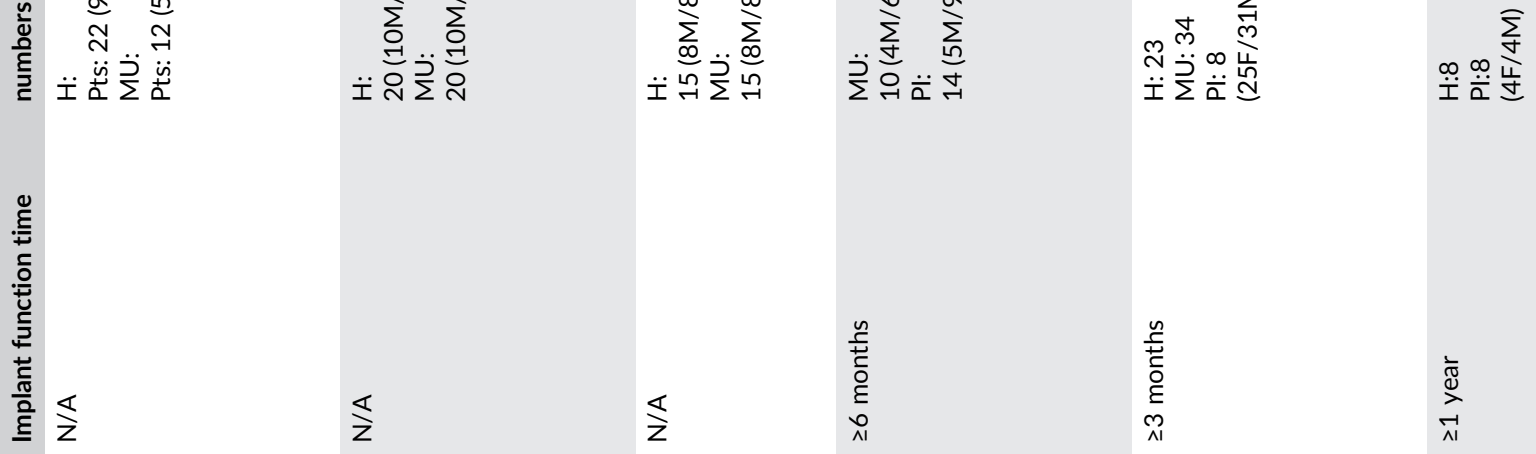

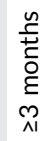
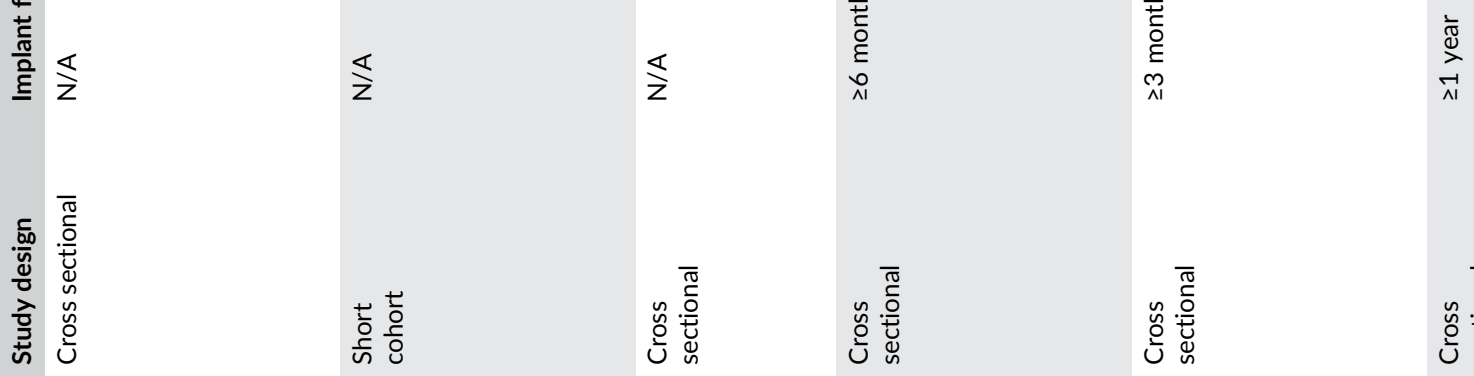

는
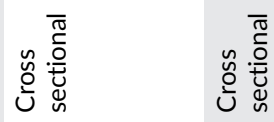

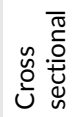

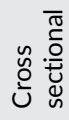

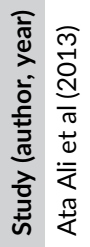

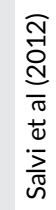
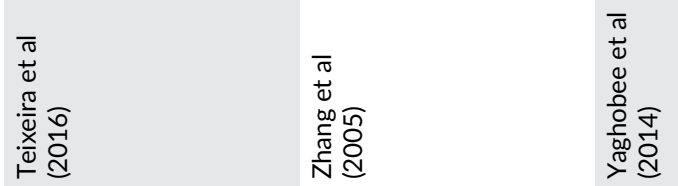


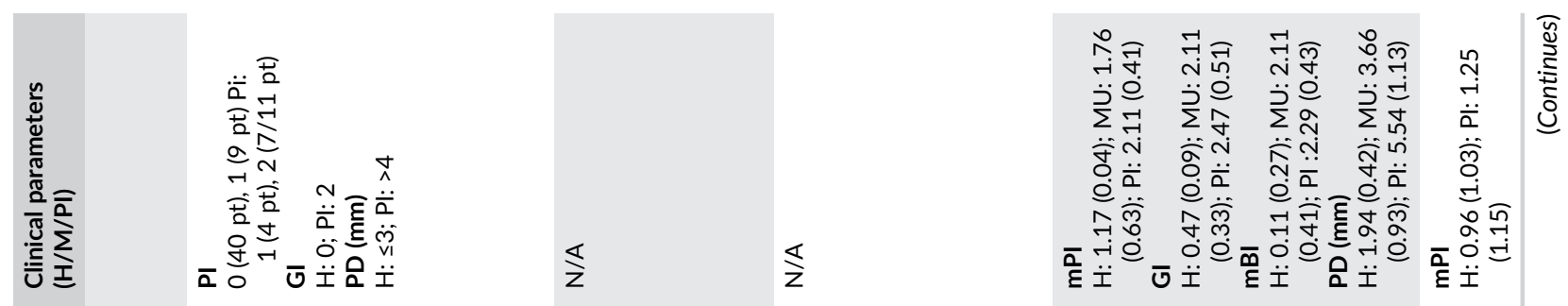

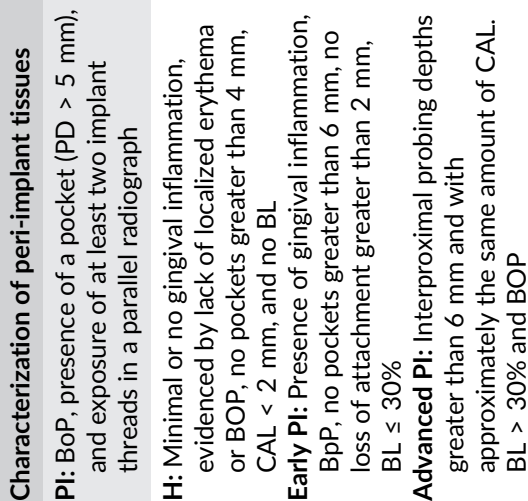
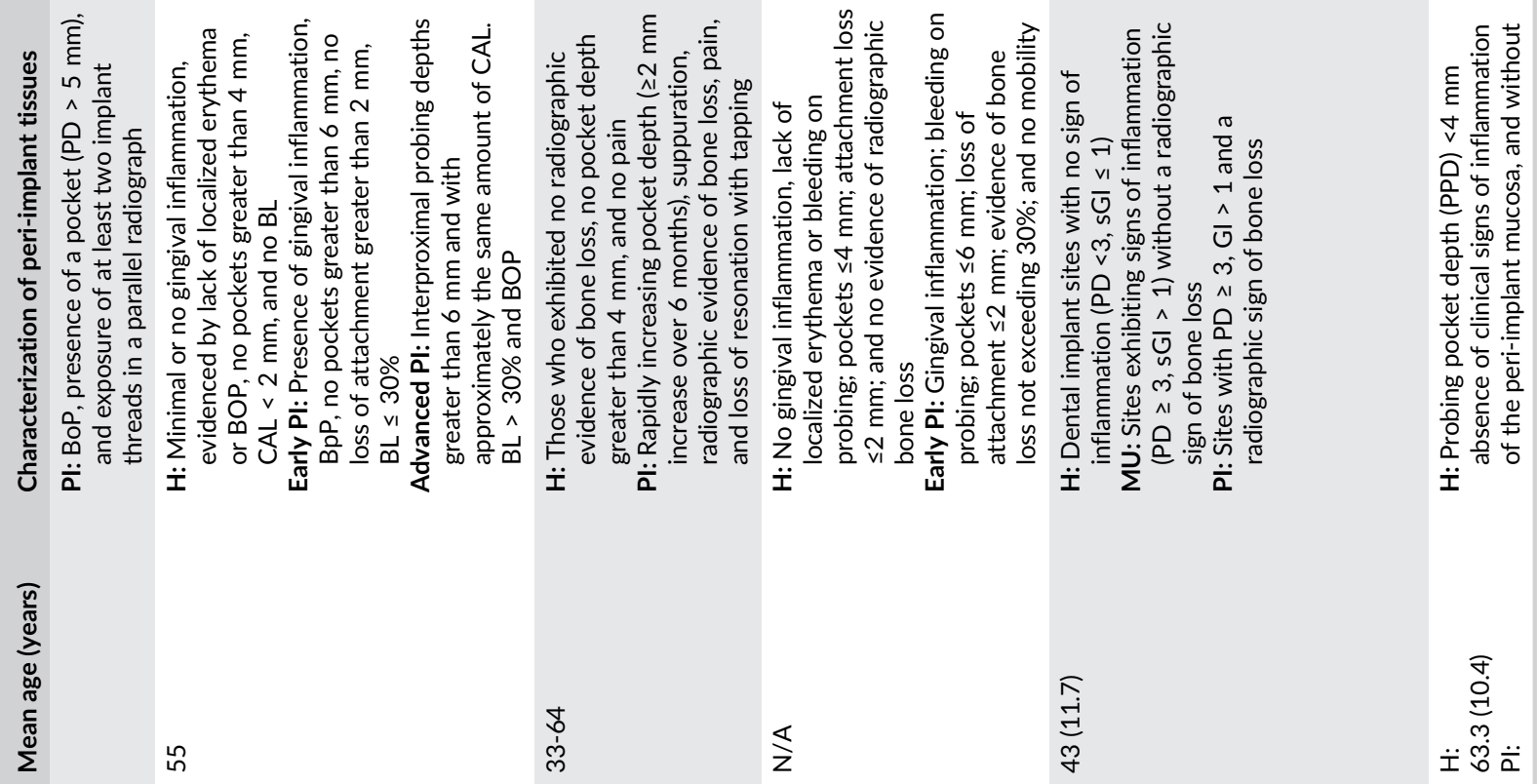

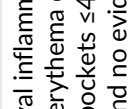

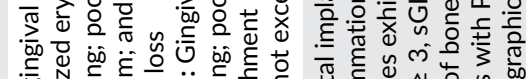

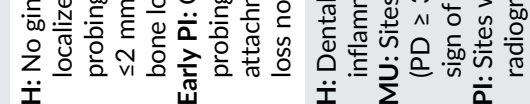

绳

ঙें

$\frac{\varangle}{z}$

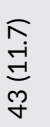

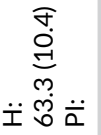

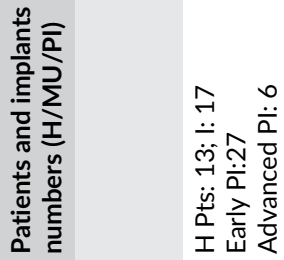

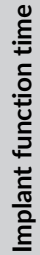

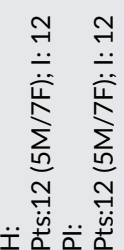

$\hat{m} \hat{m}$
$\ddot{\bar{x}} \overline{0}$

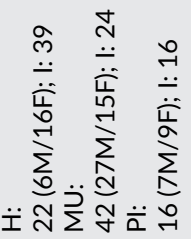

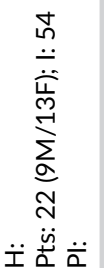

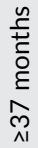

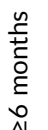

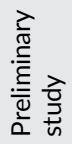

商高

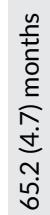

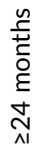

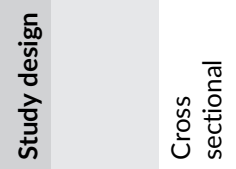

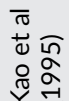

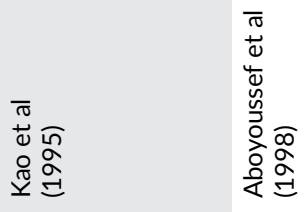

岂莣

蒠 

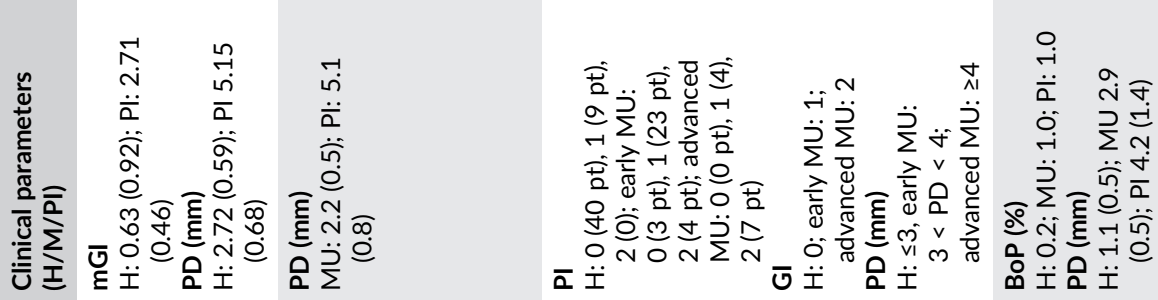

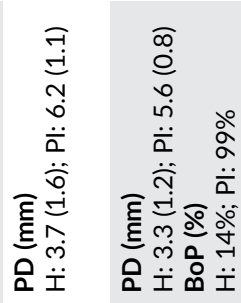
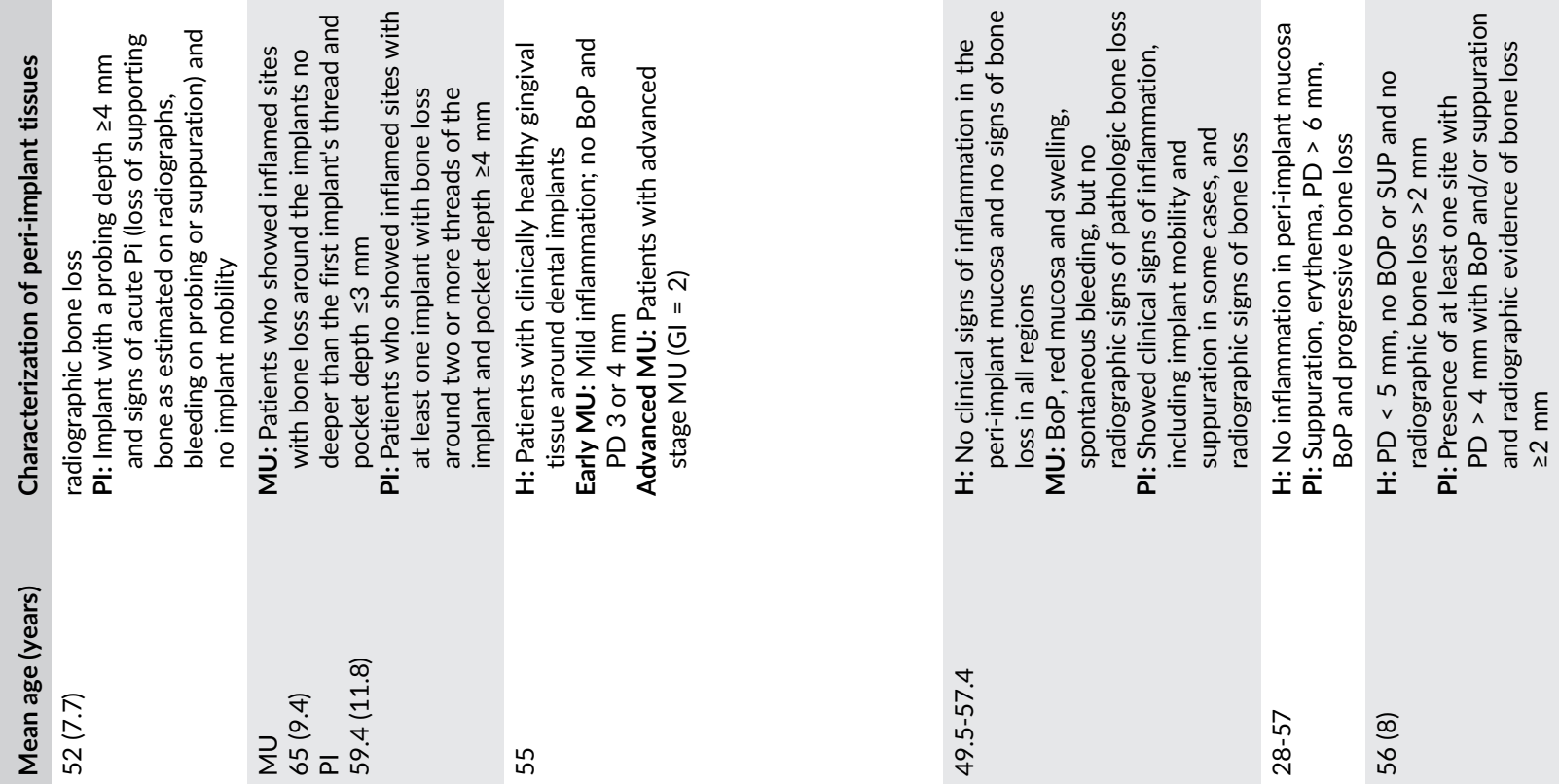

זิ่

$\begin{array}{ll}\hat{n} & \widehat{0} \\ \text { के } & \text { in }\end{array}$

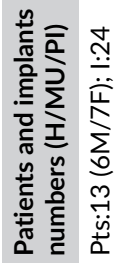

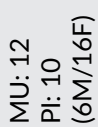
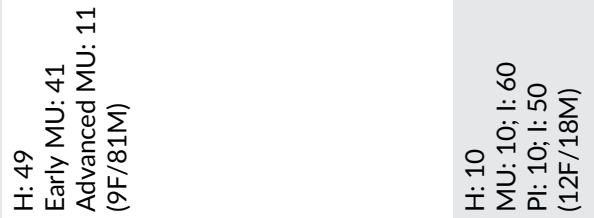

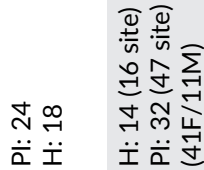

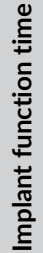

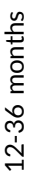

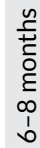

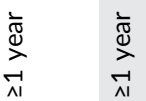

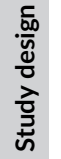

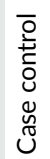

ป 옹

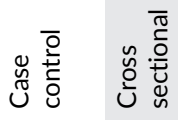




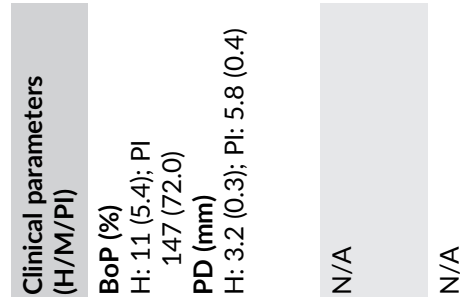

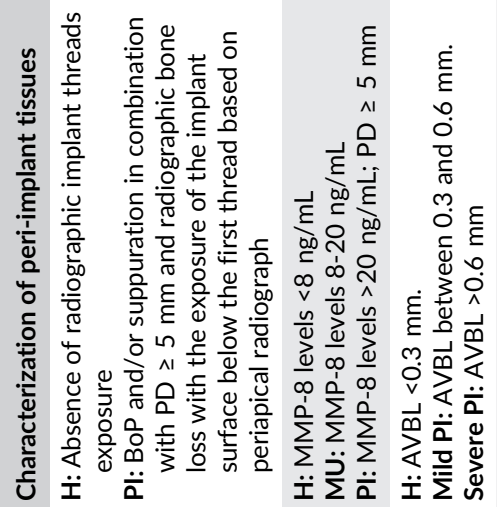

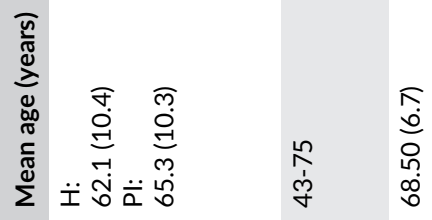

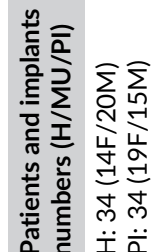

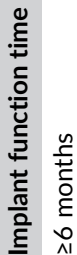

$\frac{.5}{800}$ 窟芯总

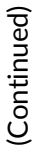

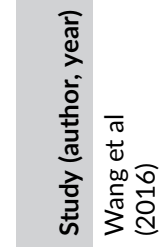

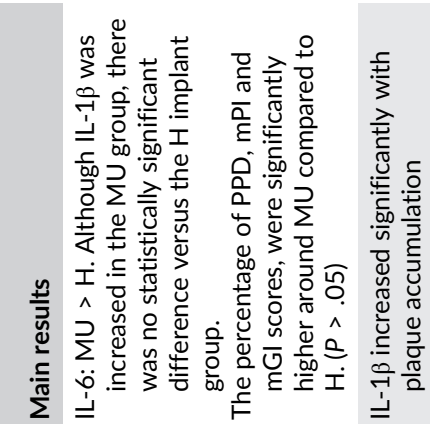

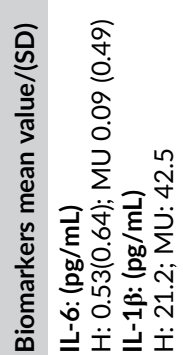

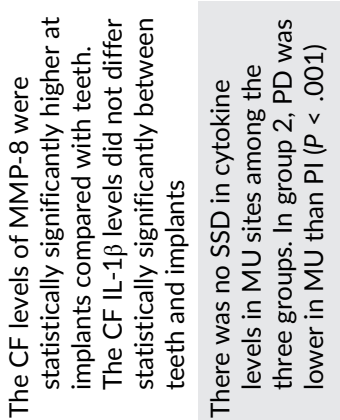

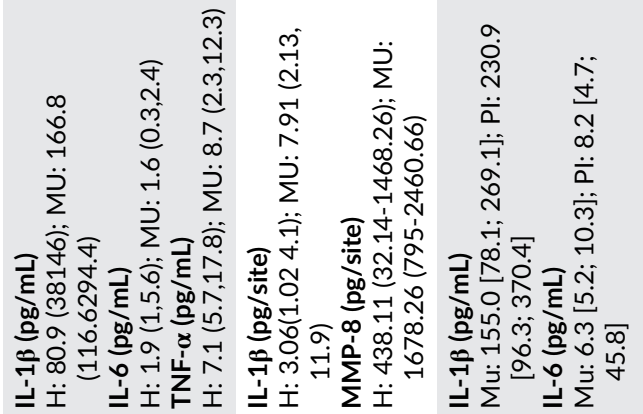

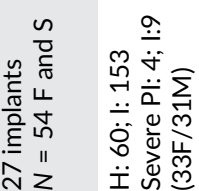<smiles>CC(C)OCCO</smiles>
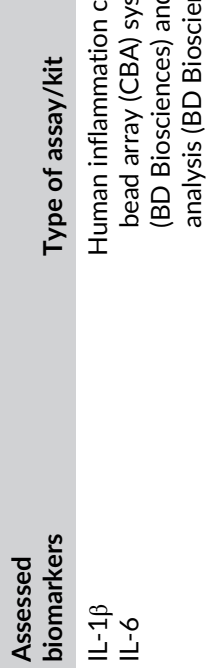

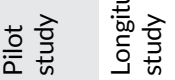
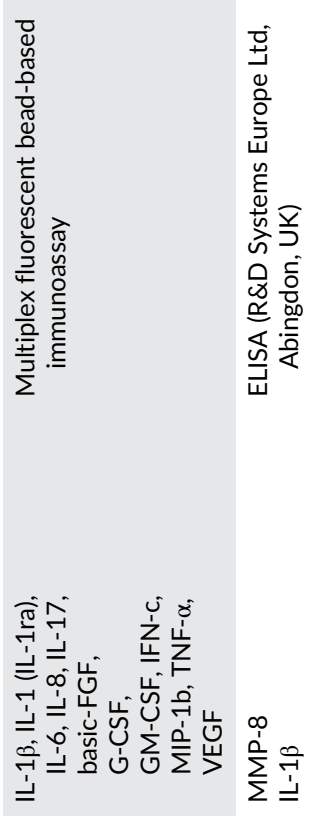
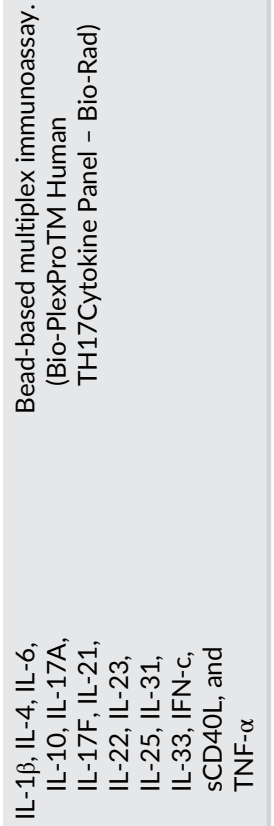

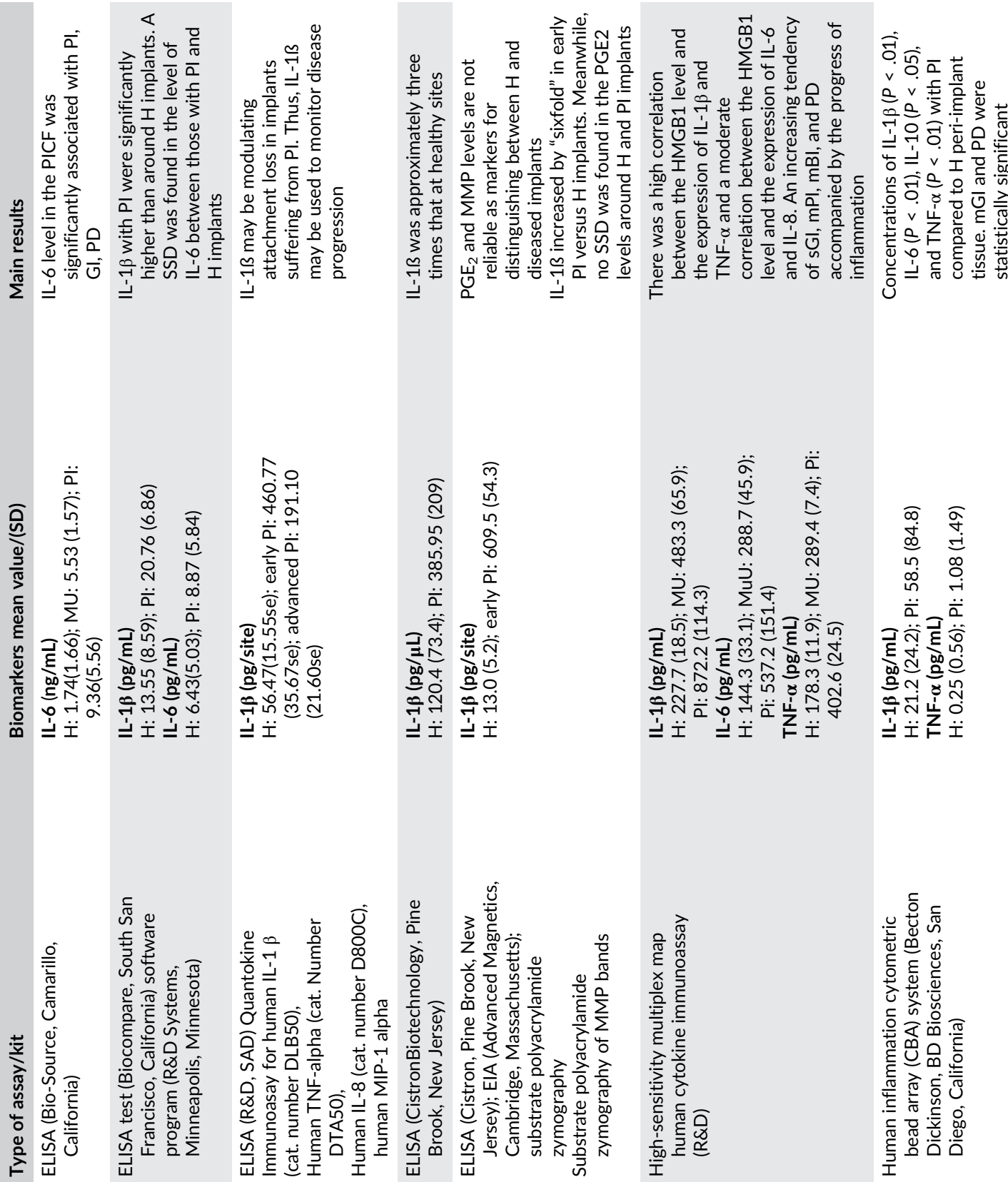

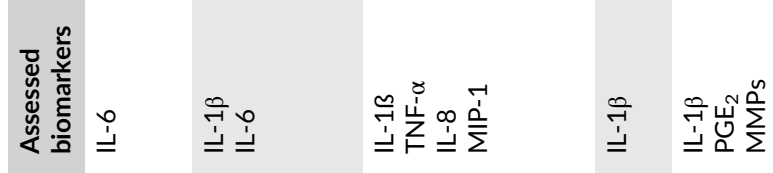
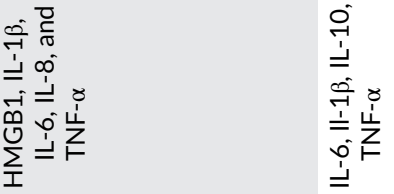

宅

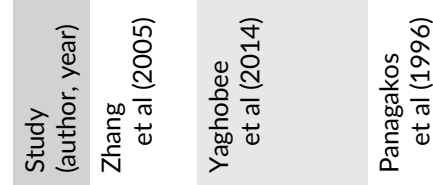

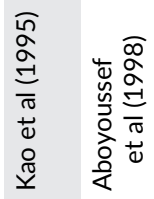

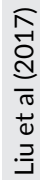

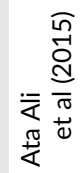



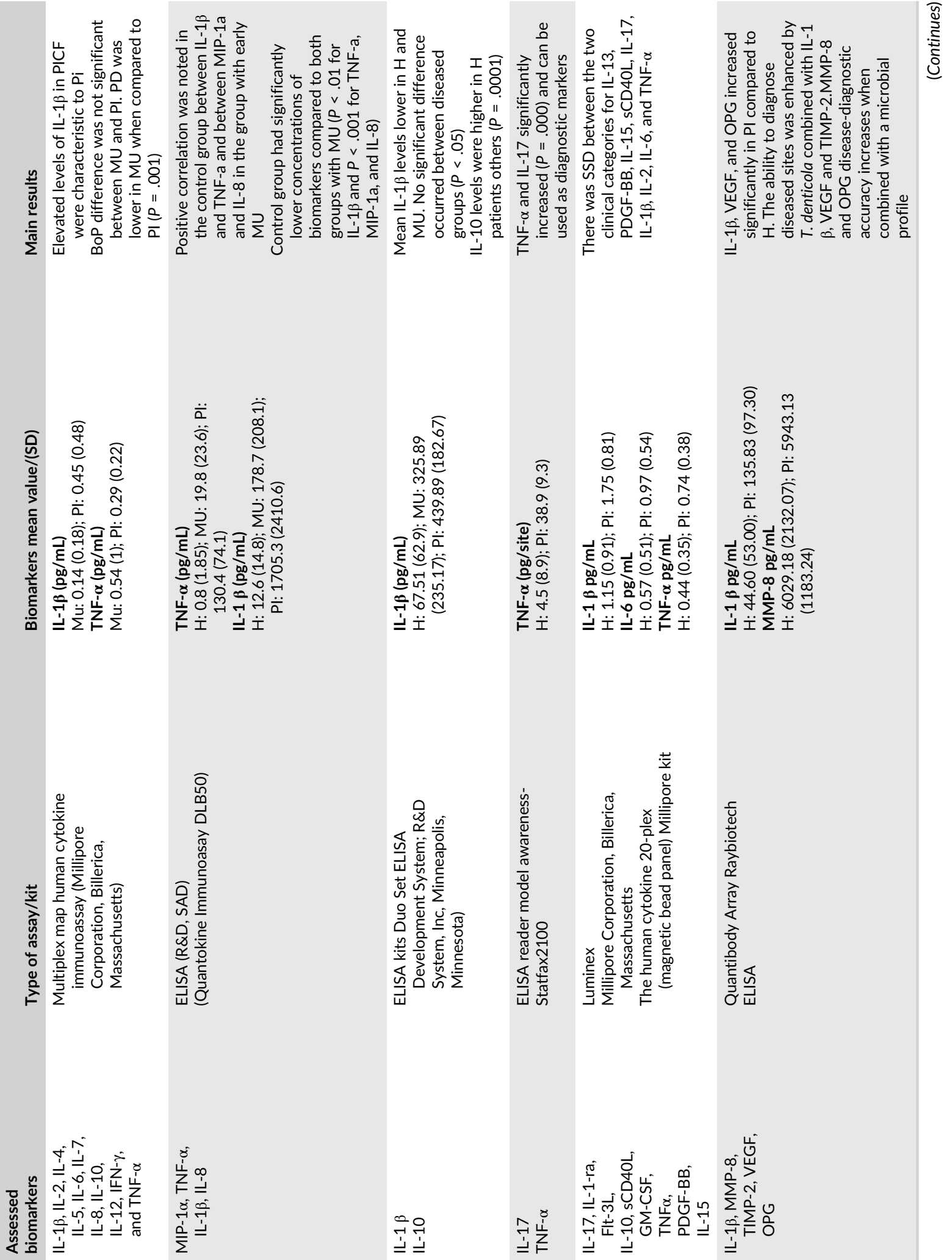

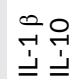
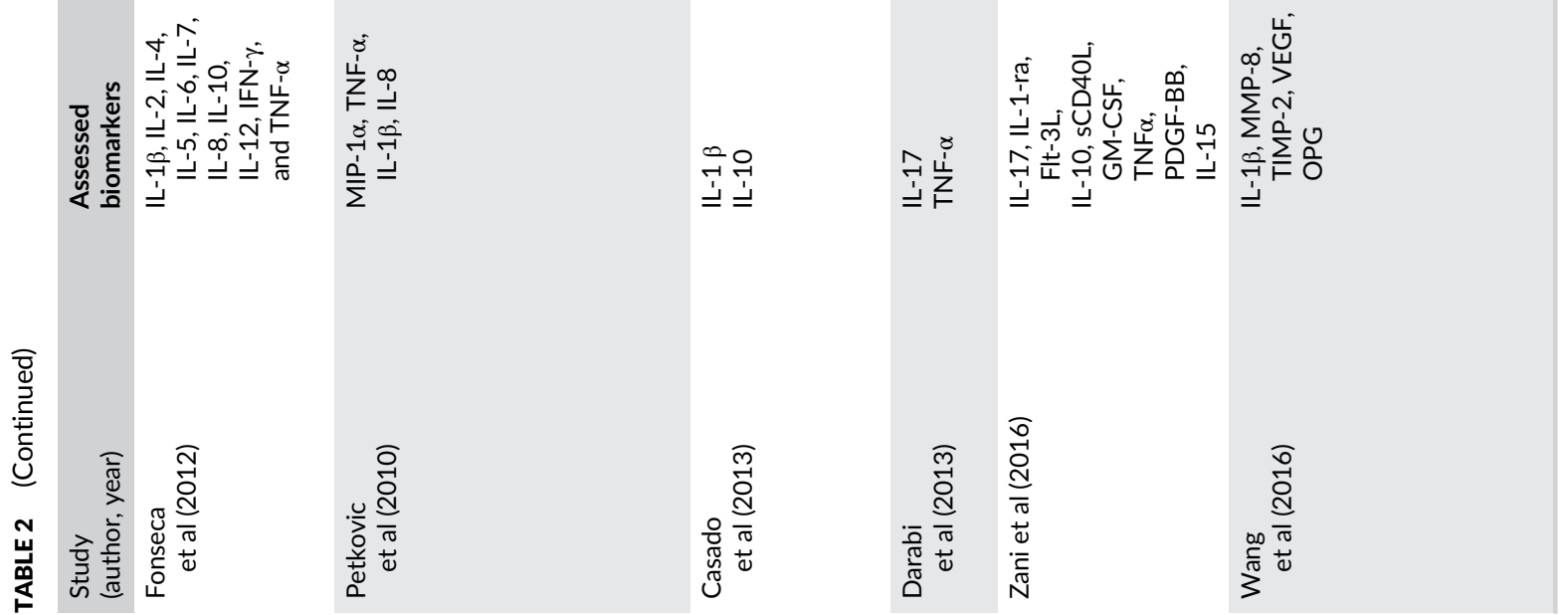


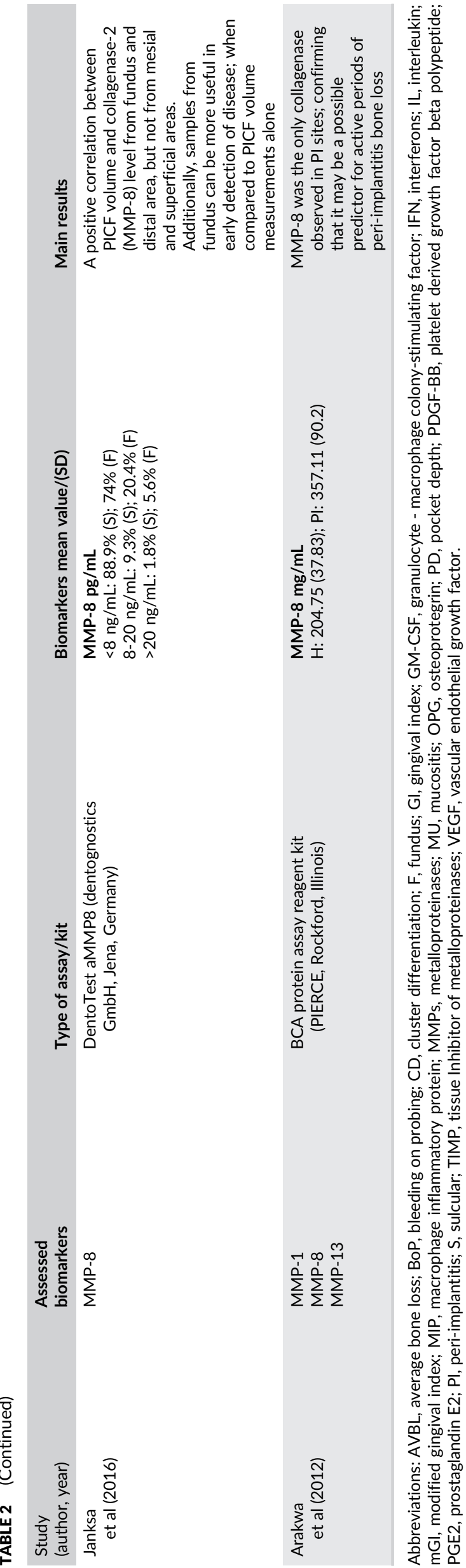

decreased effectively $\left(I^{2}=9.4 \%, P=.353\right)$, and the result remained significant (SMD: $1.21,95 \% \mathrm{Cl}: 0.89,1.53 ; P<.001)$.

Four studies ${ }^{25,35,37,40}$ compared IL-1 $\beta$ release level between implants with $\mathrm{MU}$ and $\mathrm{PI}$ (Figure $2 \mathrm{C}$ ). The result demonstrated that the IL-1 $\beta$ in PI site was similar to that in MU site (SMD: $1.52,95 \% \mathrm{Cl}$ : $-0.03,3.07 ; P=.055)$, with significant heterogeneity among these studies $\left(I^{2}=91.5 \%, P<.001\right)$. The Galbraith plot (Figure 2D) also showed that the considerable heterogeneity was generated by one study. ${ }^{25}$ The heterogeneity decreased effectively $\left(I^{2}=0.0 \%, P=.734\right)$ upon removal of that study, and the result became significant (SMD: 0.60, 95\% Cl: 0.12, 1.08; $P=.015)$.

Nine studies $2,11,25,32,34,35,38,39,41$ reported the difference in IL-1 $\beta$ between $\mathrm{H}$ and $\mathrm{PI}$ (Figure 2E). Meta-analysis of these data showed IL$\beta$ release was much higher in $\mathrm{PI}$ compared to $\mathrm{H}$ sites (SMD: $2.21,95 \%$ $\mathrm{Cl}: 1.32,3.11 ; P<.001)$. However, high degree of heterogeneity was noted $\left(I^{2}=92.6 \%, P<.001\right)$. The Galbraith plot (Figure $\left.2 F\right)$ demonstrated that the heterogeneity came from three studies. ${ }^{25,32,35}$ After excluding the data of these studies, the homogeneity test showed moderate heterogeneity among the remaining 12 studies $\left(I^{2}=43.6 \%\right.$, $P=.115)$, and results showed that the SMD was $1.06(95 \% \mathrm{Cl}$ : $0.71-1.42 ; P<.001)$.

\section{4 | Meta-analysis of IL-6 and TNF- $\alpha$}

When comparing $\mathrm{H}$ and $\mathrm{MU}$, four studies ${ }^{24,25,33,42}$ reported levels of IL- 6 and three studies ${ }^{23-25}$ reported the levels of TNF- $\alpha$. Statistical differences were found in both cytokines (Figures $3 A$ and $4 A$ ), which indicated that in $M U$ sites, the release of IL- 6 and TNF- $\alpha$ was increased (SMD: 1.17; 95\% Cl: 0.16, 3.19; $P=.031$ and SMD: 3.91; $95 \% \mathrm{Cl}: 1.13,6.70 ; P=.006$, respectively). Regarding $\mathrm{MU}$ versus $\mathrm{PI}$, there were three studies on IL- $6^{25,37,42}$ (Figure 3B). PI group showed significantly higher levels of IL- 6 than that in $\mathrm{MU}$ group (SMD = 1.46; $95 \% \mathrm{Cl}: 0.36,2.55 ; P=.009$ ). For PI versus $\mathrm{H}$, IL-6 was investigated in five studies $2,25,34,41,42$ (Figure $3 C$ ) and TNF- $\alpha$ were reported in four studies $^{23,25,34,36,41}$ (Figure 4B). Results showed that PI group has higher releasing level in both IL-6 (SMD: 1.72; 95\% CI: 0.56, 2.87; $P=.004$ ) and TNF- $\alpha$ (SMD: 3.78; 95\% Cl: 1.67, 5.89; $P$ < .001). Metaanalyses revealed high heterogeneity between these studies, with $I^{2}$ ranged from $80.3 \%$ to $98.1 \%$. The Galbraith plot (Appendix Figure A1) did not show any specific papers contributing to heterogeneity.

\section{5 | MMP-8 results}

Only five articles were included in this review investigating MMP-8 in healthy conditions versus peri-implant diseases. ${ }^{11,15,22,26,32}$ In Salvi et al 2012, MMP-8 increased significantly between $\mathrm{H}$ and MU. The three other articles compared $\mathrm{H}$ to $\mathrm{PI}{ }^{11,15,26}$ Mean values and SD of MMP-8 levels were only provided in two of the three articles ${ }^{11,26}$; thus, meta-analysis could not be performed. Nonetheless, MMP-8 was found in elevated amounts in PICF collected from a total of 85 implants; that were diagnosed with peri-implant diseases. Fifteen implants had MU and 70 had PI. Arakawa et al only found MMP-8 in PICF. The sensitivity of technique and depth of PICF samples were marked both high and significant. ${ }^{15}$ Further, a combination of 
(a)

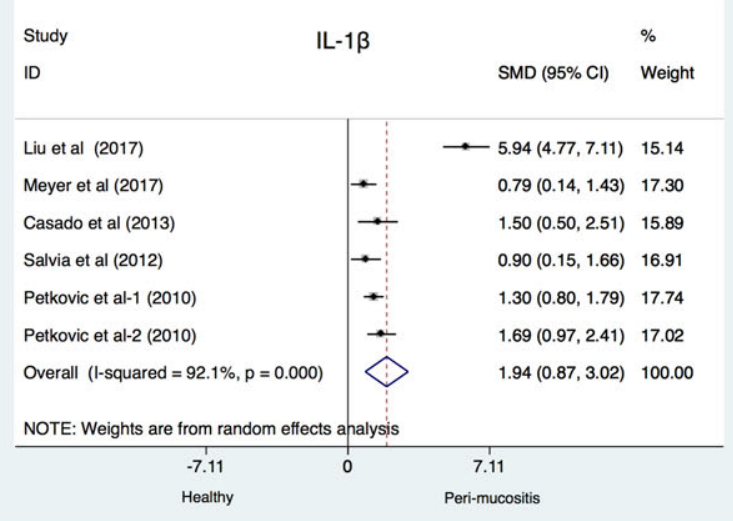

(c)

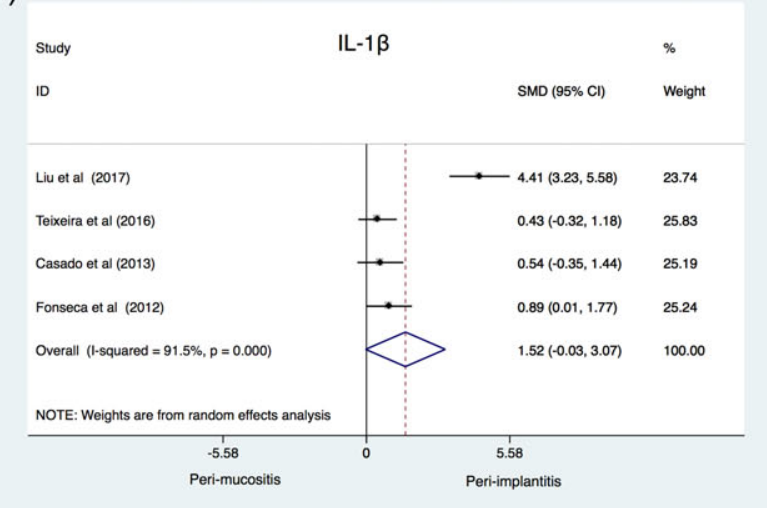

(e)

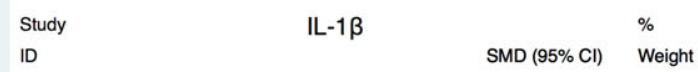

ID

Liu et al (2017)

Zani et al (2016)

Wang et al (2016)

Ata Ali et al (2015)

Yaghobee et al (2014)

Casado et al (2013)

Aboyoussef et al (1998)

Panagakos et al (1996)

Kao et al (1995)

Overall (I-squared $=92.6 \%, p=0.000)$

NOTE: Weights are from random effects analysis

$\begin{array}{ccc}-12.3 & 0 & 12.3 \\ \text { Healthy } & & \text { Peri-implantitis }\end{array}$

(b)

$\mathrm{b} / \mathrm{se}$ Linear prediction

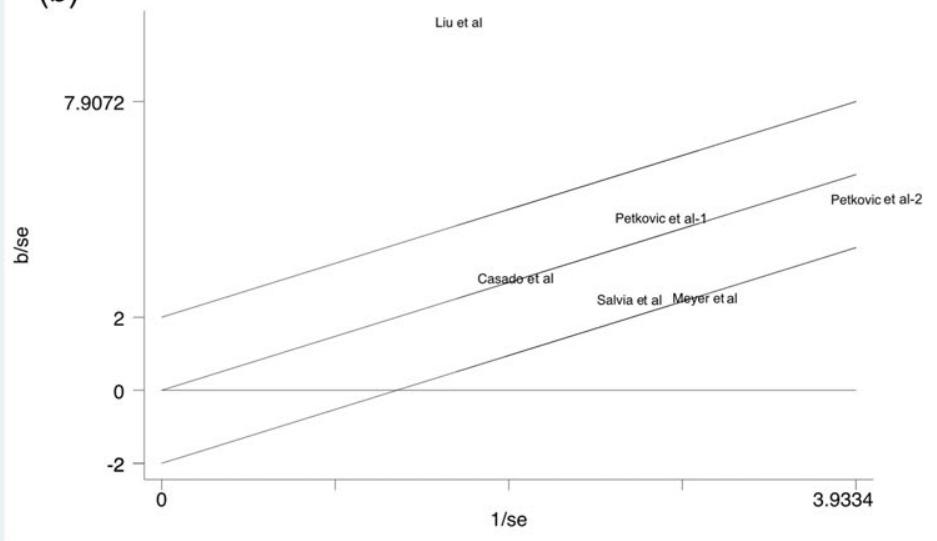

(d)

b/se

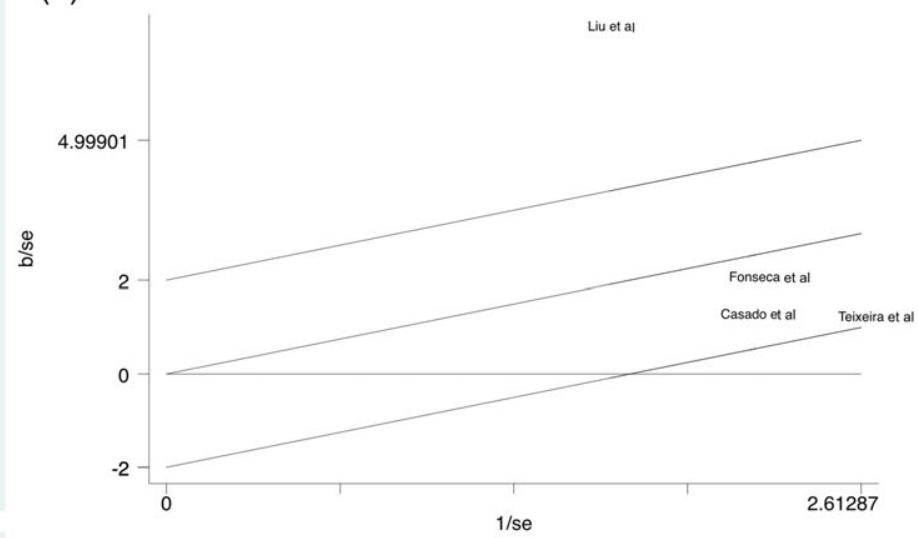

(f)
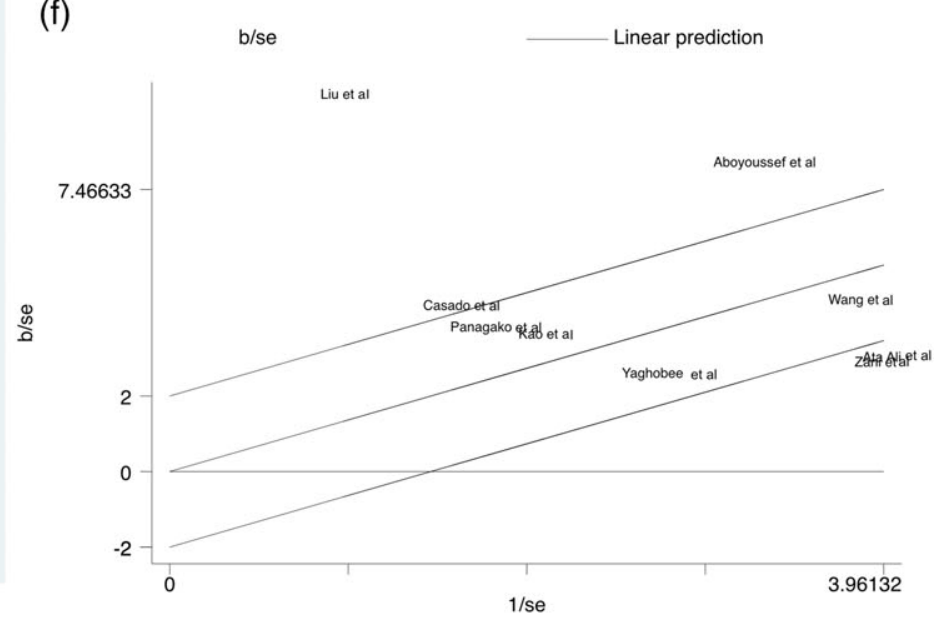

FIGURE 2 Forest plots presenting standard mean difference (SMD) of IL-1 $\beta$ comparing $\mathrm{H}$ with MU (A), MU with PI (C), and H with PI (E). Galbraith plot assessing heterogeneity of studies included in the comparison of IL-1 $\beta$ between $\mathrm{H}$ and MU (B), MU and PI (D), $\mathrm{H}$ and PI (F). $\mathrm{ES}=$ effect sizes; $\mathrm{b} / \mathrm{se}=$ standardized estimates; $1 / \mathrm{se}=$ precision

microbiological profiling and MMP-8 found to have increased the accuracy of results previously obtained. ${ }^{11}$

\subsection{Quality and risk assessment}

According to NIH Quality Assessment tool, risk assessment of bias was conducted. A study reporting less than 4 (No/NR) was defined with low risk. Any higher scores than 4 increased the bias risk and were concluded to be fair. Ten studies were regarded "good" and 9 were "fair." These were also shown in Table 3.

\section{7 | Publication bias}

The publication bias was presented by Egger test in Appendix Figure A2. For IL-1 $\beta$, there was no evidence of publication bias, according to Egger's test, in the comparison of $\mathrm{H}$ to $\mathrm{MU}$ sites $(P=.159), \mathrm{MU}$ and $\mathrm{PI}(P=.08)$. However, publication bias was found 
(a)

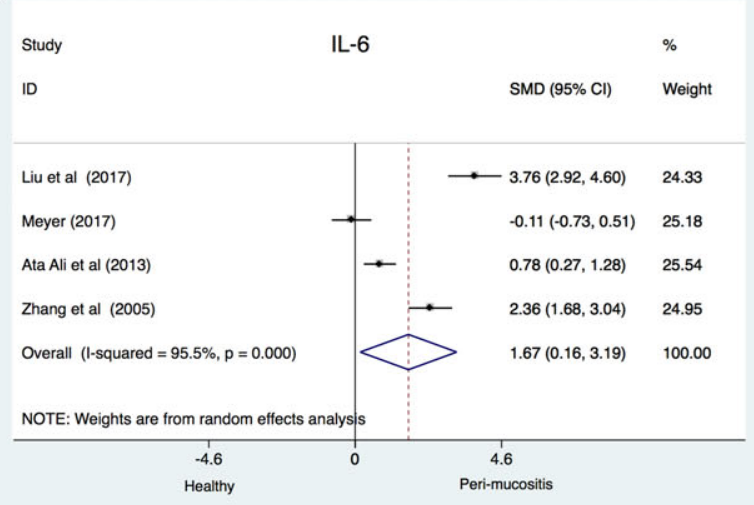

(b)

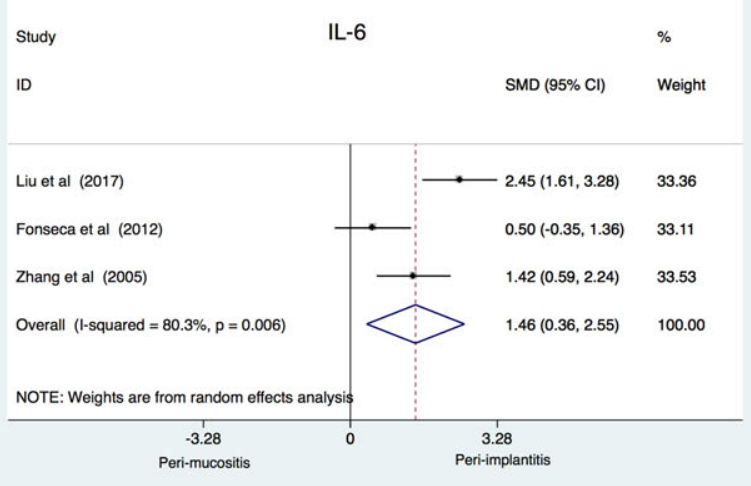

(c)

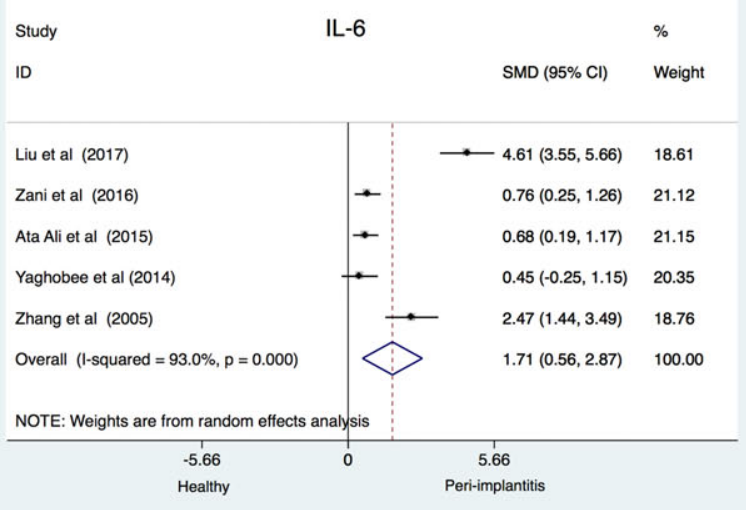

FIGURE 3 Forest plots presenting standard mean difference (SMD) of IL-6 comparing $\mathrm{H}$ with $\mathrm{MU}(\mathrm{A}), \mathrm{MU}$ with $\mathrm{PI}(\mathrm{B})$, and $\mathrm{H}$ with $\mathrm{PI}(\mathrm{C})$

in the comparison between $\mathrm{H}$ and $\mathrm{PI}(P=.013)$. Studies measuring IL6 demonstrated no publication bias in all three comparisons $(P=.234$, $.641, .08$ respectively). Egger's test, combined with funnel plots, showed that for TNF- $\alpha, \mathrm{H}$ versus $\mathrm{MU}(P=.067)$, as well as $\mathrm{H}$ versus Pl groups $(P=.082)$ failed to prove the presence of publication bias.

\section{4 | DISCUSSION}

Peri-implant soft tissues demonstrate a strong inflammatory response to plaque accumulation; influencing the occurrence and development of peri-implant diseases; MU and PI. ${ }^{11,22,43}$ Lipopolysaccharide in plaque directly stimulates macrophages, PMNs, and fibroblasts to (a)

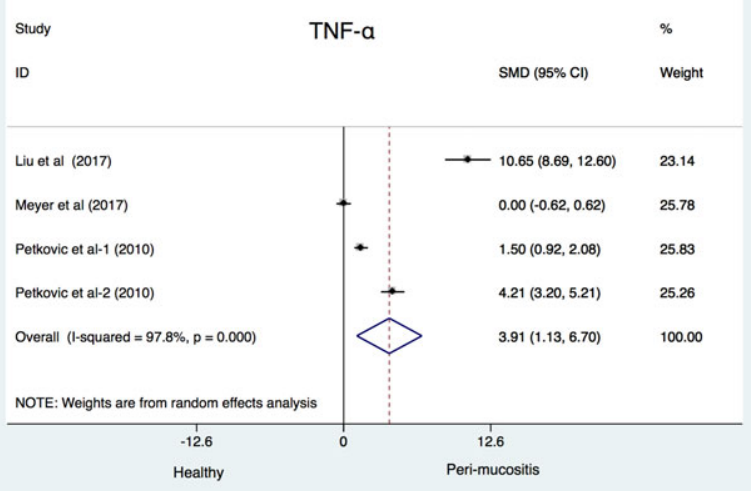

(b)

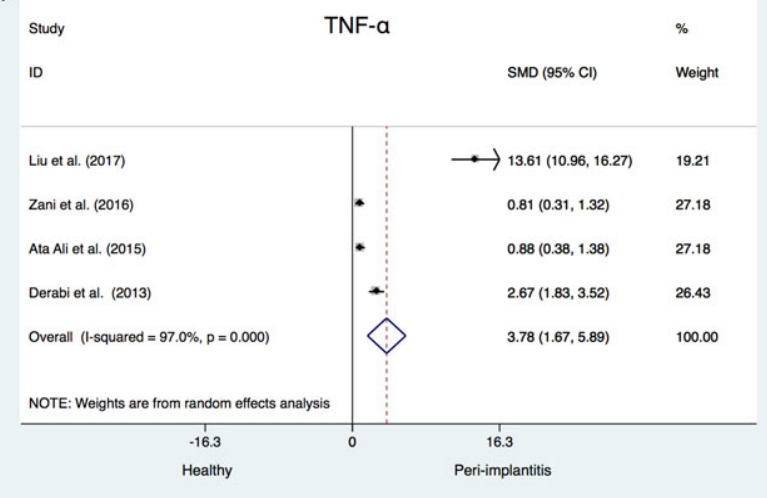

FIGURE 4 Forest plots presenting standard mean difference (SMD) of TNF- $\alpha$ comparing $\mathrm{H}$ with $\mathrm{MU}(\mathrm{A})$, and $(\mathrm{B}) \mathrm{H}$ with $\mathrm{PI}$

produce proinflammatory cytokines and MMPs. These elicit an inflammatory response that overlaps bacterial action, inducing degenerative pathways of tissues; namely, an irreversible, rapid connective tissue destruction and an alteration of osteoclast and osteoblasts' activities. ${ }^{12,17,37,44}$ Cytokines and MMPs are released in varying detectable amounts between different diseases and health conditions around implants; therefore, are recently investigated in the course of periimplant diseases. In fact, IL-1 $\beta$, IL-6, TNF- $\alpha$, and MMP-8 are the most investigated biomarkers in literature. $9,27,43,49$

Inflammation continues to occur simultaneously with changes in clinical parameters around diseased implants, such as bleeding on probing; which indicates profuse bleeding and an increased amount of exudate around the implant. Accordingly, concentrations of the selected biomarkers from 19 studies showed an enhanced host response of PICF between health, MU, and PI. Their increased levels in PICF could facilitate an early diagnosis of peri-implant disease and prediction of its onset. ${ }^{17,46}$ MMP-8 increased levels were previously associated with early implant failures. ${ }^{47,48}$ One suggested reason is polymorphism in the promoter region of MMP-8. In this meta-analysis, early implant failure was supported by a marked increase in proinflammatory cytokines IL-1 $\beta$, IL-6, and TNF- $\alpha$ expressions between $\mathrm{H}$ and $\mathrm{MU}$.

While the molecular mechanism is not fully comprehensible, it is illustrated that in the inflammatory stage of wound healing, IL-1 $\beta$ and TNF- $\alpha$ are chiefly responsible for prolonging plasminogen pathway of 
clot lysis and propagating collagenase degradative pathway. ${ }^{49}$ Some evidence suggests that IL-1 $\beta$ acts synergistically with TNF- $\alpha$ to initiate and propagate inflammation. ${ }^{50}$ This is demonstrated by the robust levels of the three investigated cytokines in $\mathrm{PI}$ when compared to $\mathrm{H}$, suggesting that they are indicative of the absence or presence of disease. Our data agree with Faot meta-analysis ${ }^{19}$; especially for IL-1 $\beta$ and TNF- $\alpha$. A correlation between pro-inflammatory cytokines and MMPs would suggest that they may cooperatively promote inflammation and tissue degradation in peri-implant diseases. ${ }^{40,48} \mathrm{IL}-1 \beta$ and TNF- $\alpha$ induce the synthesis and secretion of MMP-8; which in turn, cleaves the triple helix of collagen and collectively degrade the extracellular matrix. The biomarkers' association to one another seem to be an added benefit supporting the choice of four in this review.

Interestingly, each cytokine showed a distinct pattern of shift from $\mathrm{MU}$ to PI. IL-1 $\beta$ levels increase, but not significantly between $\mathrm{MU}$ and PI. This may suggest that there is a "peak" response to enhanced IL-1 $\beta$ levels termed substrate saturation; that is, all receptor sites being fully occupied with IL-1 $\beta$. Polymorphism in IL-1 $\beta$ gene expression could be another reason for varied responses between different individuals of the same disease category. ${ }^{38,39}$ Contrary to IL-1 $\beta$, IL-6 increases significantly between $\mathrm{MU}$ and $\mathrm{PI}(P=.009)$; suggesting that it may play a more important role in the non-linear pattern of bone loss occurring in $\mathrm{Pl}^{51} \mathrm{IL}-6$ links innate to acquired immune responses; in which it induces differentiation of activated $B$ cells in antibody-producing cells as well as naïve CD4 + T cells. It is conspicuous in chronic inflammation surrounding implants, leading to osteoclastic activation and peri-implant bone loss. ${ }^{52-54}$ These correspond to the pattern of IL-6 increase in concentration between $\mathrm{H}$ and $\mathrm{MU}$; $\mathrm{H}$ and $\mathrm{PI}^{33,55}$ To our knowledge, this is the first meta-analysis investigating IL-6 in $\mathrm{H}, \mathrm{MU}$, and PI. IL-6 was found to be more sensitive to severity of inflammation in peri-implant tissues.

Regarding TNF- $\alpha$, there were insufficient studies to compare its level between $\mathrm{MU}$ and $\mathrm{Pl}$; therefore, meta-analysis could not be conducted. Further investigations are needed to comprehend its role in inflammation and in the progression of peri-implant diseases. In qualitative assessment of MMP-8, four out of five included articles showed MMP-8 being highly elevated in peri-implant diseases along with enhanced bleeding on probing and gingival index values. Specific and sensitive tests exist that facilitate accurate detection of MMP-8 in PICF. ${ }^{11,16}$ MMP-8 shows a lot of potentials to be used in the progression of disease. ${ }^{16,26}$ In contrast, Abo Youssef found that MMPs were not reliable indicators of implant health.

In this meta-analysis, a strict inclusion criterion featured clear definitions of $\mathrm{H}, \mathrm{MU}$, and PI. Unclear definitions were either lacking a specific definition, involving therapeutic intervention prior to assessment ${ }^{47,56}$ or did not mention bone loss as the distinguishing parameter of $\mathrm{MU}$ from $\mathrm{PI}^{23}$ In the study of Panagakos, ${ }^{39} \mathrm{MU}$ was comprised of bone loss to a limit of $30 \%$. MU was stringently defined as the absence of bone loss, so this study was excluded from MU. This criterion leads to a better distinction of disease and thus enables better judgment of biomarkers use.

While many methodological features of analysis were similar in the included studies, the functioning time of implants differed. This is a limitation to relating cytokine levels to the onset of peri-implant diseases. Similarly, publication bias was found in the comparison of IL-1 $\beta$ in $\mathrm{H}$ to PI. Results show high heterogeneity $I^{2}$ varying from $80.3 \%$ to $98.1 \%$, which led to the use of the random effect model. Liu et al depict the highest heterogeneity in evaluation of IL-1 $\beta$ in all three conditions. One reason could be that cytokine levels were associated with high mobility group box 1 (HMGB1) protein increase as the principal investigated variable. ${ }^{25}$ In other studies, the main reason for high heterogeneity could be attributed to the nature of studies, that is, the majority of included studies are cross-sectional. Alternatively, longitudinal peri-implant disease monitoring, combined with a non-treatment phase, could recognize a cluster of host response biomarkers associated with breakdown of tissues. ${ }^{22,47,57,58}$

Limited evidence exists to show the number of subjects with a sufficient sample size; that is, no calculations of statistical power were documented. Among the 19 included studies, only few studies accounted for smoking habits, although smoking has been identified as a risk indicator for peri-implant inflammation. ${ }^{37,41,59,60}$ Other limitations include but are not limited to no consideration of other potential risk indicators for $\mathrm{PI}$, such as history of periodontitis and tissue phenotype. Subsequently, biomarkers' concentrations could show marked discrepancy around implants with the same diagnosed implant disease. ${ }^{35,61}$ Moreover, the type of protein assay used could affect the quality of results based on using different manufacturer products of ELISA and multiplex bead assays. Cytokine multiplex assays were found to be "comparable in sensitivity, accuracy, and reproducibility" to ELISA for the same analyte. ${ }^{62}$ Concentration values followed a similar pattern among ELISA and bead assays but yielded different absolute cytokine concentrations. A trend of varied cytokine levels was expressed in this review. ${ }^{63}$ In accordance with Khan's study, a trend is most important to monitor development and progression of disease. Finally, most studies lacked data on sensitivities and specificities to cytokines and time at which PICF samples were acquired; hence the probability of false positive or false negative results could not be calculated.

\section{5 | CONCLUSION}

Within the limitations of this study, pro-inflammatory cytokines in PICF, such as IL-1ß and IL-6, can be used as adjunct tools to clinical parameters to differentiate $\mathrm{H}$ from $\mathrm{MU}$ and $\mathrm{PI}$. The results of this review indicate moderate evidence in literature to support the use of biomarkers with peri-implant diseases. A significant increase in IL-6 is shown between $\mathrm{MU}$ and PI while IL-1 $\beta$ levels did not increase as remarkably. Future research should focus more on longitudinal monitoring of biomarkers in order to deduce a suitable range in health and disease conditions.

\section{ACKNOWLEDGMENTS}

This paper was partially supported by the University of Michigan Periodontal Graduate Student Research Fund. The authors would like to thank Dr William Giannobile for his guidance and comments. 


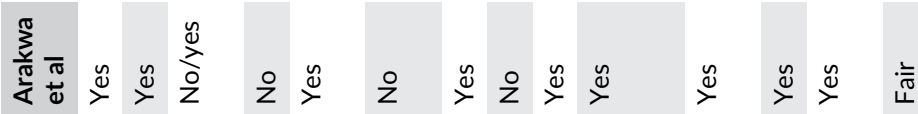

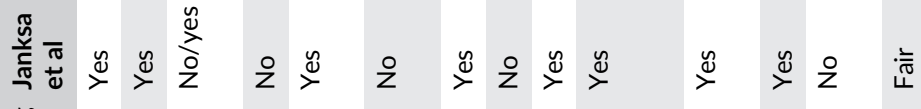

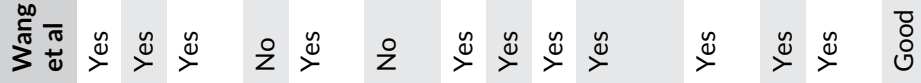

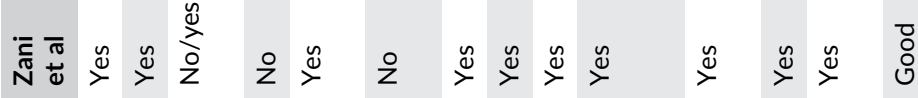

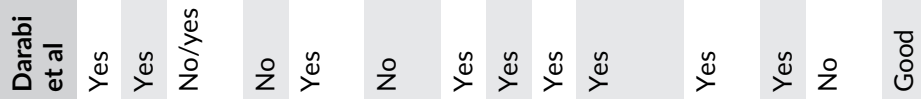

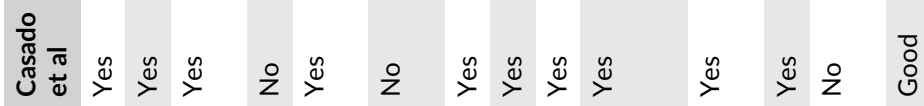

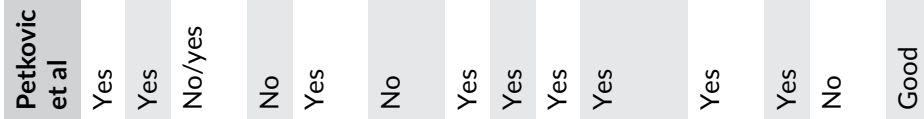

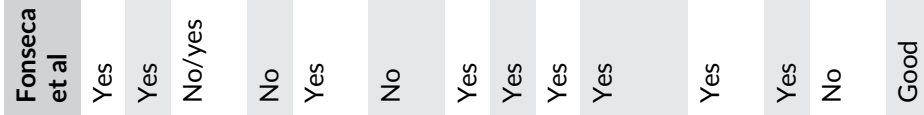

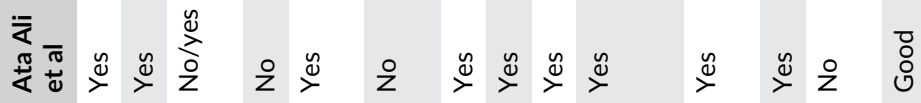

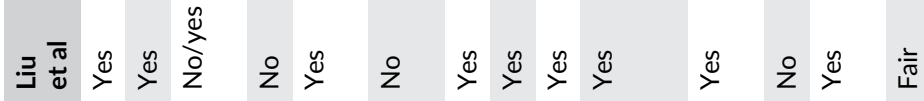
产

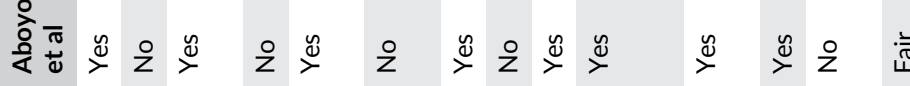

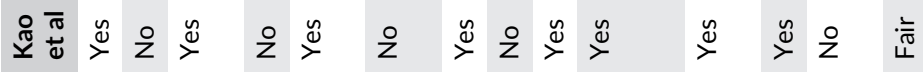
紊

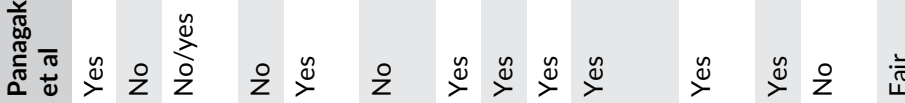

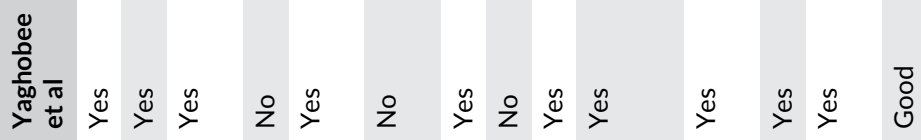

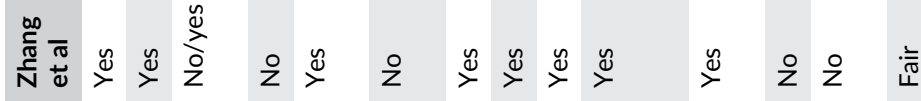

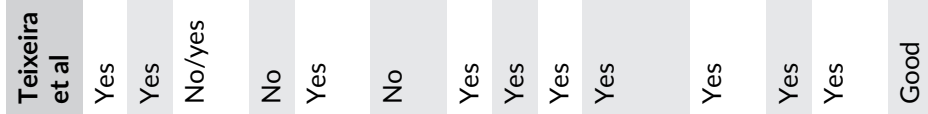

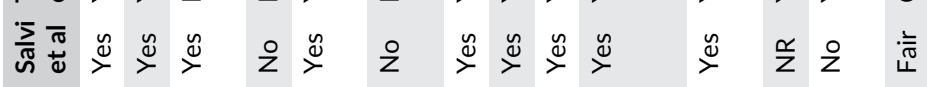

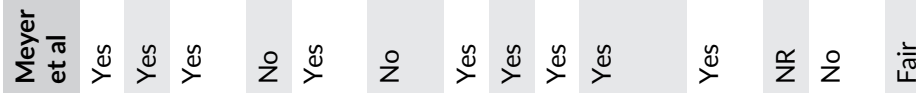

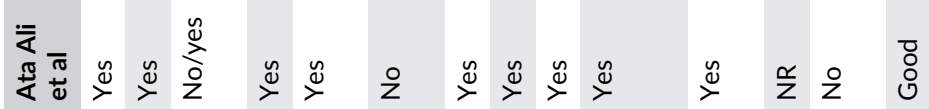

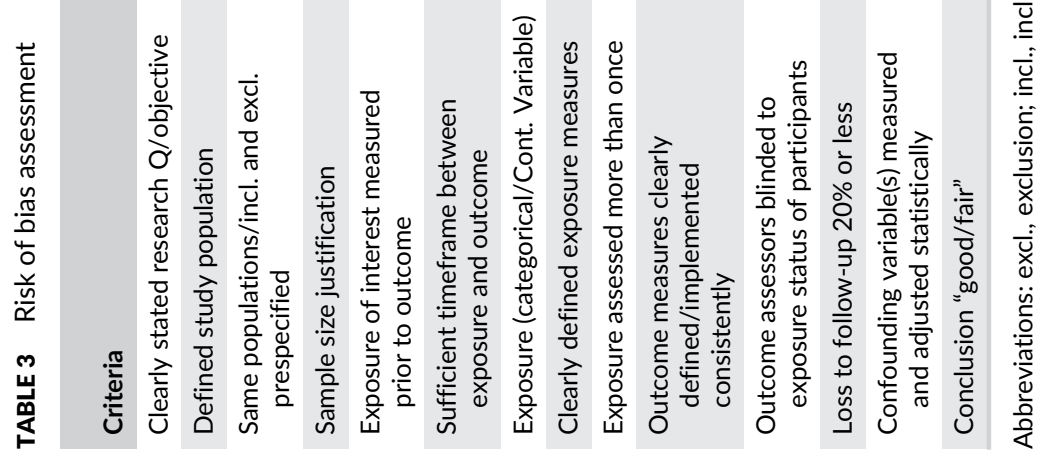



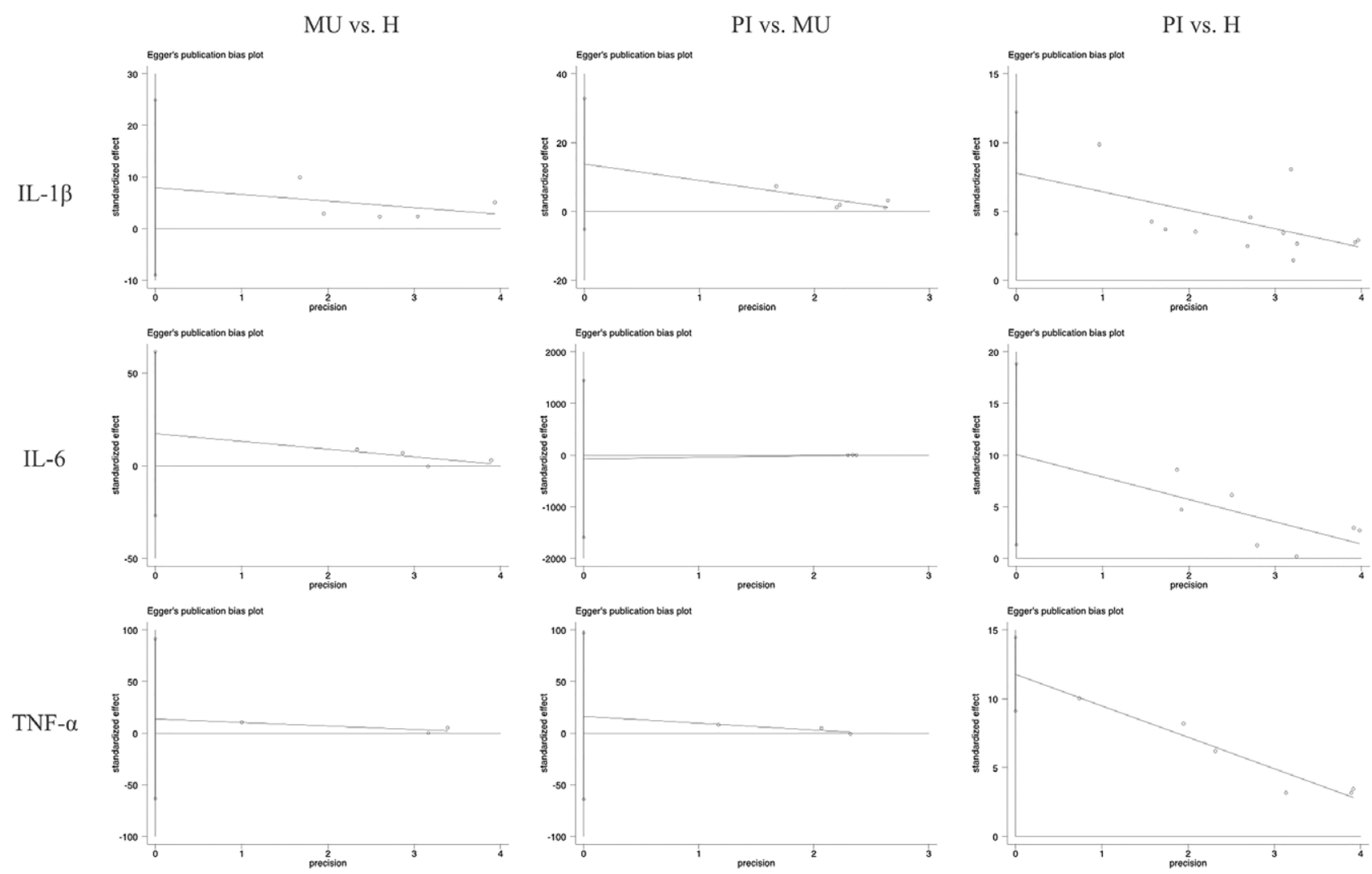

FIGURE A2 Egger linear plots assessing the public bias between studies

\section{CONFLICT OF INTEREST}

There was no conflict of interest declared. The authors do not have any financial interests, either directly or indirectly, in the products or information listed in the paper.

\section{ORCID}

Iya Ghassib (iD) https://orcid.org/0000-0002-0067-377X

Zhaozhao Chen (D) https://orcid.org/0000-0002-2188-1367

Hom-Lay Wang (D) https://orcid.org/0000-0003-4238-1799

\section{REFERENCES}

1. Zitzmann NU, Berglundh T. Definition and prevalence of peri-implant diseases. J Clin Periodontol. 2008;35:286-291.

2. Yaghobee S, Khorsand A, Rasouli Ghohroudi AA, Sanjari K, Kadkhodazadeh M. Assessment of interleukin-1beta and interleukin-6 in the crevicular fluid around healthy implants, implants with periimplantitis, and healthy teeth: a cross-sectional study. J Korean Assoc Oral Maxillofac Surg. 2014;40:220-224.

3. Roos-Jansaker AM, Lindahl C, Renvert H, Renvert S. Nine- to fourteen-year follow-up of implant treatment. Part II: presence of peri-implant lesions. J Clin Periodontol. 2006;33:290-295.

4. Jepsen S, Berglundh T, Genco R, et al. Primary prevention of periimplantitis: managing peri-implant mucositis. J Clin Periodontol. 2015; 42(suppl 16):S152-S157.

5. Schwarz F, Derks J, Monje A, Wang HL. Peri-implantitis. J Periodontol. 2018;89(suppl 1):S267-S290.

6. Mombelli A, Muller N, Cionca N. The epidemiology of peri-implantitis. Clin Oral Implants Res. 2012;23(suppl 6):67-76.

7. Stewart JE, Christenson PD, Maeder LA, Palmer MA. Reliability of filter-strip sampling of gingival crevicular fluid for volume determination using the Periotron. J Periodontal Res. 1993;28:227-230.
8. Giannobile WV, Beikler T, Kinney JS, Ramseier CA, Morelli T, Wong DT. Saliva as a diagnostic tool for periodontal disease: current state and future directions. Periodontol 2000. 2009;50:52-64.

9. Duarte PM, Serrao CR, Miranda TS, et al. Could cytokine levels in the peri-implant crevicular fluid be used to distinguish between healthy implants and implants with peri-implantitis? A systematic review. J Periodontal Res. 2016;51:689-698.

10. Mombelli A, Lang NP. Clinical parameters for the evaluation of dental implants. Periodontol 2000. 1994;4:81-86.

11. Wang HL, Garaicoa-Pazmino C, Collins A, Ong HS, Chudri R, Giannobile WV. Protein biomarkers and microbial profiles in periimplantitis. Clin Oral Implants Res. 2016;27:1129-1136.

12. Li JY, Wang HL. Biomarkers associated with periimplant diseases. Implant Dent. 2014;23:607-611.

13. Bhardwaj S, Prabhuji ML. Comparative volumetric and clinical evaluation of peri-implant sulcular fluid and gingival crevicular fluid. J Periodontal Implant Sci. 2013;43:233-242.

14. Kivela-Rajamaki MJ, Teronen OP, Maisi $P$, et al. Laminin-5 gamma2-chain and collagenase-2 (MMP-8) in human peri-implant sulcular fluid. Clin Oral Implants Res. 2003;14:158-165.

15. Janska E, Mohr B, Wahl G. Correlation between peri-implant sulcular fluid rate and expression of collagenase2 (MMP8). Clin Oral Investig. 2016;20:261-266.

16. Sorsa T, Gursoy UK, Nwhator S, et al. Analysis of matrix metalloproteinases, especially MMP-8, in gingival creviclular fluid, mouthrinse and saliva for monitoring periodontal diseases. Periodontol 2000. 2016; 2000, 70:142-163.

17. Murata M, Tatsumi J, Kato Y, et al. Osteocalcin, deoxypyridinoline and interleukin-1beta in peri-implant crevicular fluid of patients with periimplantitis. Clin Oral Implants Res. 2002;13:637-643.

18. Nomura $T$, Ishii A, Shimizu $H$, et al. Tissue inhibitor of metalloproteinases-1, matrix metalloproteinases- 1 and -8 , and collagenase activity levels in peri-implant crevicular fluid after implantation. Clin Oral Implants Res. 2000;11:430-440.

19. Faot F, Nascimento GG, Bielemann AM, Campao TD, Leite FR, Quirynen M. Can peri-implant crevicular fluid assist in the diagnosis of 
peri-implantitis? A systematic review and meta-analysis. J Periodontol. 2015;86:631-645.

20. Konttinen YT, Lappalainen R, Laine P, Kitti U, Santavirta S, Teronen O. Immunohistochemical evaluation of inflammatory mediators in failing implants. Int J Periodontics Restorative Dent. 2006;26:135-141.

21. Schierano G, Pejrone G, Brusco P, et al. TNF-alpha TGF-beta2 and IL1 beta levels in gingival and peri-implant crevicular fluid before and after de novo plaque accumulation. J Clin Periodontol. 2008;35 532-538.

22. Salvi GE, Aglietta M, Eick S, Sculean A, Lang NP, Ramseier CA. Reversibility of experimental peri-implant mucositis compared with experimental gingivitis in humans. Clin Oral Implants Res. 2012;23:182-190.

23. Petkovic AB, Matic SM, Stamatovic NV, et al. Proinflammatory cytokines (IL-1beta and TNF-alpha) and chemokines (IL-8 and MIP-1alpha) as markers of peri-implant tissue condition. Int J Oral Maxillofac Surg. 2010;39:478-485.

24. Meyer S, Giannopoulou C, Courvoisier D, Schimmel M, Muller F, Mombelli A. Experimental mucositis and experimental gingivitis in persons aged 70 or over. Clinical and biological responses. Clin Oral Implants Res. 2017;28:1005-1012.

25. Liu J, Li R, Rausch-Fan TLX, Wang M. High mobility group box 1 protein level as a novel biomarker for the development of peri-implant disease. Sci Rep. 2017;7:7027.

26. Arakawa H, Uehara J, Hara ES, et al. Matrix metalloproteinase-8 is the major potential collagenase in active peri-implantitis. J Prosthodont Res. 2012;56:249-255

27. Javed F, Al-Hezaimi K, Salameh Z, Almas K, Romanos GE. Proinflammatory cytokines in the crevicular fluid of patients with peri-implantitis. Cytokine. 2011;53:8-12.

28. Harbord RM, Egger M, Sterne JA. A modified test for small-study effects in meta-analyses of controlled trials with binary endpoints. Stat Med. 2006;25(20):3443-3457.

29. Higgins JPT, Green S, Cochrane Collaboration. Cochrane Handbook for Systematic Reviews of Interventions. Chichester, England: WileyBlackwell; 2008.

30. 30.Higgins JP, Thompson SG. Quantifying heterogeneity in a metaanalysis. Stat Med. 2002;21(11):1539-1558.

31. Galbraith RF. A note on graphical presentation of estimated odds ratios from several clinical trials. Stat Med. 1988;7(8):889-894.

32. Aboyoussef H, Carter C, Jandinski JJ, Panagakos FS. Detection of prostaglandin E2 and matrix metalloproteinases in implant crevicular fluid. Int J Oral Maxillofac Implants. 1998;13:689-696.

33. Ata-Ali J, Flichy-Fernandez AJ, Ata-Ali F, Penarrocha-Diago $M$, Penarrocha-Diago M. Clinical, microbiologic, and host response characteristics in patients with peri-implant mucositis. Int J Oral Maxillofac Implants. 2013;28:883-890.

34. Ata-Ali J, Flichy-Fernandez AJ, Alegre-Domingo T, Ata-Ali F, Palacio J, Penarrocha-Diago M. Clinical, microbiological, and immunological aspects of healthy versus peri-implantitis tissue in full arch reconstruction patients: a prospective cross-sectional study. BMC Oral Health. 2015;15:43.

35. Casado PL, Canullo L, de Almeida Filardy A, Granjeiro JM, Barboza EP, Leite Duarte ME. Interleukins 1 beta and 10 expressions in the periimplant crevicular fluid from patients with untreated periimplant disease. Implant Dent. 2013;22:143-150.

36. Darabi E, Kadkhoda Z, Amirzargar A. Comparison of the levels of tumor necrosis factor-alpha and interleukin-17 in gingival crevicular fluid of patients with peri-implantitis and a control group with healthy implants. Iran J Allergy Asthma Immunol. 2013;12:75-80.

37. Fonseca FJ, Moraes Junior $M$, Lourenco EJ, Teles Dde $M$, Figueredo CM. Cytokines expression in saliva and peri-implant crevicular fluid of patients with peri-implant disease. Clin Oral Implants Res. 2014:25:e68-e72.

38. Kao RT, Curtis DA, Richards DW, Preble J. Increased interleukin-1 beta in the crevicular fluid of diseased implants. Int J Oral Maxillofac Implants. 1995;10:696-701.

39. Panagakos FS, Aboyoussef H, Dondero R, Jandinski JJ. Detection and measurement of inflammatory cytokines in implant crevicular fluid: a pilot study. Int J Oral Maxillofac Implants. 1996;11:794-799.

40. Teixeira MKS, Lira-Junior R, Telles DM, Lourenco EJV, Figueredo CM. Th17-related cytokines in mucositis: is there any difference between peri-implantitis and periodontitis patients? Clin Oral Implants Res. 2017;28:816-822.

41. Zani SR, Moss K, Shibli JA, et al. Peri-implant crevicular fluid biomarkers as discriminants of peri-implant health and disease. J Clin Periodontol. 2016;43:825-832.

42. Zhang Y, Wang C, Jinbu Y, Itoh H, Kusama M. Increased IL-6 levels in peri-implant crevicular fluid correlate with peri-implantitis. Oral Med Pathol. 2005;10:95-99.

43. Sorsa T, Mantyla P, Ronka $\mathrm{H}$, et al. Scientific basis of a matrix metalloproteinase-8 specific chair-side test for monitoring periodontal and peri-implant health and disease. Ann N Y Acad Sci. 1999;878: 130-140.

44. Dennison DK, Van Dyke TE. The acute inflammatory response and the role of phagocytic cells in periodontal health and disease. Periodontol 2000. 1997;14:54-78.

45. Renvert S, Widen C, Persson GR. Cytokine expression in peri-implant crevicular fluid in relation to bacterial presence. J Clin Periodontol. 2015;42:697-702.

46. Lachmann S, Kimmerle-Muller E, Axmann D, Scheideler L, Weber H, Haas R. Associations between peri-implant crevicular fluid volume, concentrations of crevicular inflammatory mediators, and composite IL-1A -889 and IL-1B +3954 genotype. A cross-sectional study on implant recall patients with and without clinical signs of peri-implantitis. Clin Oral Implants Res. 2007;18:212-223.

47. Basegmez C, Yalcin S, Yalcin F, Ersanli S, Mijiritsky E. Evaluation of periimplant crevicular fluid prostaglandin E2 and matrix metalloproteinase-8 levels from health to periimplant disease status: a prospective study. Implant Dent. 2012;21:306-310.

48. Thierbach R, Maier K, Sorsa T, Mantyla P. Peri-implant sulcus fluid (PISF) matrix metalloproteinase (MMP) -8 levels in Peri-Implantitis. J Clin Diagn Res. 2016;10:ZC34-ZC38.

49. Aukhil I, Pettersson E, Suggs C. Periodontal wound healing in the absence of periodontal ligament cells. J Periodontol. 1987;58:71-77.

50. Dinarello CA. Proinflammatory cytokines. Chest. 2000;118:503-508.

51. Derks J, Schaller D, Hakansson J, Wennstrom JL, Tomasi C Berglundh T. Peri-implantitis - onset and pattern of progression. J Clin Periodontol. 2016;43:383-388.

52. Hirano T, Akira S, Taga T, Kishimoto T. Biological and clinical aspects of interleukin 6. Immunol Today. 1990;11:443-449.

53. Tanaka T, Narazaki M, Kishimoto T. IL-6 in inflammation, immunity, and disease. Cold Spring Harb Perspect Biol. 2014;6:a016295.

54. Tanaka K, Hashizume M, Mihara M, Yoshida H, Suzuki M, Matsumoto Y. Anti-interleukin-6 receptor antibody prevents systemic bone mass loss via reducing the number of osteoclast precursors in bone marrow in a collagen-induced arthritis model. Clin Exp Immunol. 2014;175:172-180.

55. Severino VO, Beghini M, de Araujo MF, et al. Expression of IL-6, IL10, IL-17 and IL-33 in the peri-implant crevicular fluid of patients with peri-implant mucositis and peri-implantitis. Arch Oral Biol. 2016;72: 194-199.

56. Luo L, Xie P, Gong P, Tang XH, Ding Y, Deng LX. Expression of HMGB1 and HMGN2 in gingival tissues, GCF and PICF of periodontitis patients and peri-implantitis. Arch Oral Biol. 2011;56:1106-1111.

57. Zhang J, Niu J, Yang J. Interleukin-6, interleukin-8 and interleukin-10 in estimating the severity of acute pancreatitis: an updated meta-analysis. Hepatogastroenterology. 2014;61:215-220.

58. Heitz-Mayfield LJ. Peri-implant diseases: diagnosis and risk indicators. J Clin Periodontol. 2008;35:292-304.

59. Strietzel FP, Reichart PA, Kale A, Kulkarni M, Wegner B, Kuchler I. Smoking interferes with the prognosis of dental implant treatment: a systematic review and meta-analysis. J Clin Periodontol. 2007;34: 523-544.

60. Rakic M, Lekovic V, Nikolic-Jakoba N, Vojvodic D, PetkovicCurcin A, Sanz M. Bone loss biomarkers associated with periimplantitis. A cross-sectional study. Clin Oral Implants Res. 2013;24: 1110-1116.

61. de Jager W, te Velthuis H, Prakken BJ, Kuis W, Rijkers GT. Simultaneous detection of 15 human cytokines in a single sample of stimulated peripheral blood mononuclear cells. Clin Diagn Lab Immunol. 2003;10:133-139. 
62. Khan SS, Smith MS, Reda D, Suffredini AF, McCoy JP Jr. Multiplex bead array assays for detection of soluble cytokines: comparisons of sensitivity and quantitative values among kits from multiple manufacturers. Cytometry B Clin Cytom. 2004;61: 35-39.

63. Melo RF, Lopes BM, Shibli JA, Marcantonio E Jr, Marcantonio RA, Galli GM. Interleukin-1beta and interleukin-6 expression and gene polymorphisms in subjects with peri-implant disease. Clin Implant Dent Relat Res. 2012;14:905-914.
How to cite this article: Ghassib I, Chen Z, Zhu J, Wang H-L. Use of IL-1 $\beta$, IL-6, TNF- $\alpha$, and MMP-8 biomarkers to distinguish peri-implant diseases: A systematic review and metaanalysis. Clin Implant Dent Relat Res. 2019;21:190-207. https://doi.org/10.1111/cid.12694 